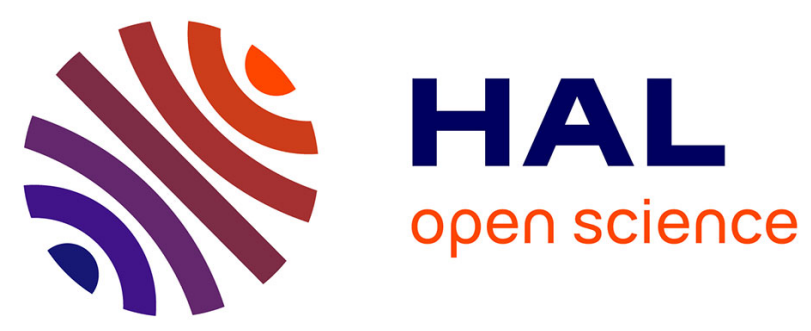

\title{
New record of Melomys burtoni (Mammalia, Rodentia, Murinae) from Halmahera (North Moluccas, Indonesia): a review of Moluccan Melomys
}

Pierre-Henri Fabre, Yuli S. Fitriana, Gono Semiadi, Marie Pagès, Ken Aplin, Nanang Supriatna, Kristofer M. Helgen

\section{To cite this version:}

Pierre-Henri Fabre, Yuli S. Fitriana, Gono Semiadi, Marie Pagès, Ken Aplin, et al.. New record of Melomys burtoni (Mammalia, Rodentia, Murinae) from Halmahera (North Moluccas, Indonesia): a review of Moluccan Melomys. Mammalia, 2018, 82 (3), pp.218 - 247. 10.1515/mammalia-2016-0137. hal-02620910

\section{HAL Id: hal-02620910 \\ https://hal.inrae.fr/hal-02620910}

Submitted on 26 May 2020

HAL is a multi-disciplinary open access archive for the deposit and dissemination of scientific research documents, whether they are published or not. The documents may come from teaching and research institutions in France or abroad, or from public or private research centers.
L'archive ouverte pluridisciplinaire HAL, est destinée au dépôt et à la diffusion de documents scientifiques de niveau recherche, publiés ou non, émanant des établissements d'enseignement et de recherche français ou étrangers, des laboratoires publics ou privés. 
Pierre-Henri Fabre*, Yuli S. Fitriana, Gono Semiadi, Marie Pagès, Ken Aplin, Nanang Supriatna and Kristofer M. Helgen

\section{New record of Melomys burtoni (Mammalia, Rodentia, Murinae) from Halmahera (North Moluccas, Indonesia): a review of Moluccan Melomys}

DOI 10.1515/mammalia-2016-0137

Received September 16, 2016; accepted April 11, 2017; previously published online June 22, 2017

\begin{abstract}
Mosaic-tailed rodents of the genus Melomys belong to the Australasian old endemic murine radiation and exhibit a rat-like morphology with arboreal or scansorial specializations. Here we report a new population of Melomys burtoni from the island of Halmahera (in the North Moluccas, Indonesia). Our molecular phylogenetic results highlight close relationships and recent evolutionary divergences among $M$. burtoni from Halmahera and the Australo-Papuan taxa M. burtoni and M. lutillus and other Moluccan taxa, including M. paveli. Multivariate as well as geometric morphometric analyses of cranial, and dental features support the recognition of $M$. burtoni from Halmahera as a slightly distinctive insular population, preventing us from elevating it as a new taxa. This population is recorded from lowland secondary forest and forest
\end{abstract}

\footnotetext{
*Corresponding author: Pierre-Henri Fabre, Institut des Sciences de l'Evolution (ISEM, UMR 5554 CNRS/UM2/IRD), Université Montpellier II, Place E. Bataillon, CC 064, 34095 Montpellier Cedex 5, France; and National Museum of Natural History, Smithsonian Institution, P.O. Box 37012, MRC 108, Washington, DC 20013-7012, USA, e-mail: phfmourade@gmail.com

Yuli S. Fitriana, Gono Semiadi and Nanang Supriatna: Research Center for Biology, Indonesian Institute of Sciences (LIPI), JL. Raya Jakarta, Bogor Km. 46, Cibinong 16911 Bogor, Indonesia Marie Pagès: Institut des Sciences de l'Evolution (ISEM, UMR 5554 CNRS/UM2/IRD), Université Montpellier II, Place E. Bataillon, CC 064, 34095 Montpellier Cedex 5, France; Laboratoire de génétique des microorganismes, Université de Liège, 4000 Liège, Belgique; and INRA, UMR CBGP (INRA/IRD/Cirad/Montpellier SupAgro), Campus International de Baillarguet, CS 30016, 34988 Montferriersur-Lez Cedex, France

Ken Aplin: National Museum of Natural History, Smithsonian Institution, P.O. Box 37012, MRC 108, Washington, DC 20013-7012, USA

Kristofer M. Helgen: South Australian Museum, North Terrace, Adelaide 5000, Australia; and Australian Centre for Evolutionary Biology and Biodiversity, University of Adelaide, Adelaide 5000, Australia
}

edge habitats in south-central Halmahera. As with other Moluccan endemic murines, colonization by an AustraloPapuan ancestor and subsequent isolation is the probable mode of diversification for $M$. burtoni in Halmahera. The discovery of Melomys in Halmahera fills a previously puzzling gap in knowledge of the murine fauna of the Moluccas and the biogeography of the Wallacean region.

Keywords: biodiversity; biogeography; Halmahera; IndoPacific; Melomys burtoni group; Moluccas; systematics.

\section{Introduction}

“... this remarkable absence [Melomys from Halmahera] remains unexplained."

Tim Flannery (1995b: 147)

Beginning especially with the travels of renowned naturalist Alfred Russel Wallace (Wallace 1869), the Indo-Pacific region has been the focus of numerous studies concerning biotic evolution and biogeography of island archipelagos (Hall 1998, Hall and Holloway 1998, Metcalfe et al. 2001, Lohman et al. 2011). Biogeographic study in the region is especially compelling because it serves as a transition zone between the highly distinctive faunal communities of Asia and Australia, which have fascinated biologists for centuries. Wallace (1876) was the first to rigorously document these differences across the scope of the archipelago, and identify the zoogeographical boundary, today known as the Wallace Line, between these two continental source pools in the region. The Moluccas comprise a series of island archipelagos east of Sulawesi and west of New Guinea, and are an important geographic component of the biologically unique transition zone of Wallacea, the area of the Indonesian archipelago lying between the Wallace Line and New Guinea. The Moluccas exhibit very high species-level endemism (Flannery 1995a, Coates and Bishop 1997, Monk et al. 1997, De Jong 1998, Stattersfield et al. 1998). However, relatively little mammalogical 
fieldwork, especially on nonvolant mammals, has been carried out in this remote part of Indonesia (Thomas 1911, 1920, 1921a,b, 1922b, Kellogg 1945, Kitchener and Maryanto 1993, 1995, Flannery 1995a, Kitchener and Suyanto 1996, Helgen 2003, Fabre et al. 2013).

The most diverse nonvolant mammal group within the Moluccas is the rodent family Muridae, represented by at least 16 endemic species (Amori et al. 2008) belonging to two major lineages. First, the rats (tribe Rattini), represented in the Moluccas by the genera Rattus, Nesoromys, and Halmaheramys, with five endemic Moluccan species so far described: Rattus elaphinus (Sody 1941) of Taliabu (Sula Islands); Rattus feliceus (Thomas 1920) of Seram; Rattus morotaiensis (Kellogg 1945) of the North Moluccas (Morotai, Halmahera, Bacan); Nesoromys ceramicus (Thomas 1920) of Seram; and Halmaheramys bokimekot (Fabre et al. 2013) of Halmahera; plus various additional undescribed species from the North Moluccas, Sangihe, and Sula Islands (Flannery 1995a, Fabre et al. 2013, G. Musser, in litt., K. Helgen and K. Aplin, in litt., Fabre pers. comment). Secondly, the "older endemic" Hydromyini, a lineage characteristic of the Australo-Papuan region (Lecompte et al. 2008, Rowe et al. 2008, Aplin and Helgen 2010, Bryant et al. 2011), represented in the Moluccas by the genera Melomys (M.), and Uromys, with 11 endemic Moluccan species so far described: M. aerosus (Thomas, 1920), M. fraterculus (Thomas 1920), M. fulgens (Thomas 1920), and M. paveli (Helgen 2003) of Seram; M. bannisteri (Kitchener and Maryanto, 1993) of the Kai Islands; M. caurinus (Thomas 1921a) and M. talaudium (Thomas 1921b) of the Talaud Islands; M. cooperae (Kitchener, in Kitchener and Maryanto 1995) and M. howi (Kitchener, in Kitchener and Suyanto 1996) of the Tanimbar Islands; M. obiensis (Thomas 1911) of Obi and Bisa; plus Uromys siebersi (Thomas 1923) of the Kai Islands.

Both of these groups have undergone adaptive radiations within the Australasian region, both involving Wallacea. These radiations have produced a species-rich group of rats (Rattus and allies) found throughout Southeast Asia and the Australo-Papuan region (Musser and Carleton 2005, Pagès et al. 2010, Rowe et al. 2011), and the remarkable adaptive radiation of the Sahulian Old Endemics (Rowe et al. 2008). Biodiversity of murine rodents is remarkable (1) on the very large Wallacean island of Sulawesi (e.g. Musser 1982, 1987, 1990, 1991, Musser and Holden 1991, Musser and Durden 2002, Esselstyn et al. 2012) (which also has a notable endemic radiation of squirrels: Musser et al. 2010), (2) on the large Moluccan island of Seram (Helgen 2003), and (3) on the islands of Timor and Flores in Nusa Tenggara (although much recent diversity is now apparently extinct; but see Musser 1981, Aplin and Helgen 2010). In contrast, very little is known about rodent communities from most other Wallacean islands. On current knowledge, the large Moluccan islands of Halmahera $\left(17,780 \mathrm{~km}^{2}\right)$, and Buru $\left(9505 \mathrm{~km}^{2}\right)$ seem particularly depauperate compared to other Indo-Pacific archipelagoes (Laurie and Hill 1954, Corbet and Hill 1992, Flannery 1995a, Heaney et al. 1998, Amori et al. 2008), either reflecting a pattern of faunal impoverishment relative to other island groups or likely indicating considerable currently undocumented biodiversity (Helgen 2003, Fabre et al. 2013), as discussed below.

Melomys is the most diverse and widely distributed genus in the Moluccan fauna and in the Australo-Papuan region more broadly. Species of Melomys are small to medium sized arboreal or scansorial rats native to Australia and New Guinea and adjacent archipelagos, including the Moluccas, Bismarcks, and Solomon Islands (Thomas 1922a,b, Rümmler 1938, Menzies 1996, Musser and Carleton 2005). They are characterized by fine, soft coats, rounded ears, raised tail scales arranged in a mosaic fashion, broad hind feet, a slightly prehensile tail and various cranio-dental features (Rümmler 1936, 1938, Tate 1951, Menzies 1973, 1990, 1996, Groves and Flannery 1994, Flannery 1995b, Musser and Lunde 2009). Under current taxonomy (Musser and Carleton 2005), Melomys comprises about 23 species. The most recent taxonomic revision of Melomys, by Menzies (1996), re-defined the scope and content of the genus, removed many species to other genera (Mammelomys Menzies 1996; Paramelomys Rümmler 1936; and Protochromys Menzies 1996). Menzies (1996) subsequently divided the remaining species into two divisions - the M. cervinipes division (cervinipes, capensis, burtoni, frigicola, lutillus), and the M. rufescens division (leucogaster, rufescens). However, Menzies' revision dealt mainly with New Guinean taxa rather than including all Australian and insular forms. Menzies' (1996) M. cervinipes division is characterized by (1) a long anterior palatine foramina; (2) larger tail scales that are smoother and less raised; (3) three hairs per tail scale; and (4) pure white or greyish belly fur. In contrast, members of Menzies' (1996) M. rufescens division have (1) short anterior palatine foramina; (2) raised and sculptured small tail scales; (3) one hair per tail scale; and (4) pure white belly fur, at least on the anterior and posterior region. Musser and Carleton (2005) recently suggested three possible affiliations for the Moluccan species: (1) a M. cervinipes group including M. bannisteri, $M$. fraterculus, $M$. howi and M. obiensis; (2) a $M$. leucogaster group including $M$. caurinus and $M$. talaudium; and (3) a M. rufescens cluster with M. paveli and M. cooperae. The taxonomy of Melomys is therefore rather problematic, mainly due to a lack of exhaustive revision for such a speciose genus as well as the absence of an extensive molecular phylogenetic framework. 
Bryant et al. (2011) recently reported a molecular phylogeny of Melomys and related genera, confirming that Paramelomys constitutes a separate generic lineage from Melomys, and that Melomys, as currently defined, is paraphyletic due to the inclusion of Solomys Thomas 1922a (with Melomys leucogaster recovered as the sister lineage to Solomys) (but see also Bryant 2013). The phylogenetic results of Bryant et al. (2011) revealed (1) unexpected phylogenetic diversity within the $M$. cervinipes group, (2) a new, taxonomically uncharacterized major Australian lineage, and (3) support for the monophyly of $M$. burtoni and $M$. lutillus as closely-related taxonomic units. Because of the low molecular divergences among $M$. burtoni and M. lutillus, their conspecificity was suggested. Confirming this last result, however, will require further molecular sequencing across a wider taxonomic sampling. Inclusion of poorly known Moluccan endemics will be crucial as they represent half of the genus diversity.

Despite the presence of an endemic species (M. obiensis) on the islands of Obi and Bisa, south of Halmahera, and two endemic species (M. caurinus and M. talaudium) in the Talaud Islands, to the northwest of Halmahera, previous efforts to survey the rodent fauna of Halmahera and its major satellite islands (which include the larger islands of Bacan and Morotai and the smaller islands of Ternate, Tidore, and Kayoa) have not revealed Melomys (Kellogg 1945, Flannery 1995a, Hasagawa and Syaffrudin 1995a,b), which has been considered a puzzling absence. Even studies of Holocene zooarchaeological deposits from Halmahera, indicating greater past rodent diversity in the North Moluccas, have not revealed Melomys (Flannery et al. 1995, Bellwood et al. 1998), posing a biogeographic riddle: how can such a widely distributed genus as Melomys be lacking from the Halmaheran fauna? As Flannery (1995a) observed, "there are no records [of Melomys] ... from ... the Halmahera group (which lie between the Talauds and Seram), and this remarkable absence remains unexplained" (p. 147) and "information gathered from local inhabitants as well as trapping results indicate that [Melomys obiensis] (and indeed all Melomys) is absent from the nearby Halmahera group" (p. 142).

Description of an endemic Halmaheran Melomys population, the subject of this paper, is thus an important addition to current knowledge of Moluccan small mammal biodiversity that fills in a previously confusing distributional gap. During the most recent efforts to survey rodents in Halmahera, in 2010, and 2013, a team from the Museum Zoologicum Bogoriense collected specimens of Melomys for the first time, from the region of Halmahera Tengah (Central Halmahera; see Figure 1), representing a new distinctive population. In response, we developed both classical and geometric morphometric approaches for all the species recorded in the Moluccas region. Using both mitochondrial and nuclear DNA from two Moluccan endemics in combination with the existing Bryant et al. (2011) dataset, we infer a molecular phylogeny. Using these phylogenetic and morphological frameworks, we addressed the following questions: (1) what is the molecular systematic affinity of the newly discovered Halmaheran Melomys population (2) What are the morphological differences of this new Moluccan endemic population? (3) What is the most likely scenario of dispersal events required to explain Halmahera colonization by this population?

\section{Materials and methods}

\section{Fieldwork in Halmahera}

Fieldwork in Halmahera was undertaken during JanuaryFebruary 2010, June-July 2010 and September 2013. Rodents were captured in folding (Sherman) rat traps. Rodent capture and handling in the field followed animal care and use guidelines recommended by the American Society of Mammalogists (Sikes et al. 2011). Permits to collect scientific specimens were requested and provided by the State Ministry of Research and Technology (RISTEK) and the Ministry of Forestry, Republic of Indonesia. Specimens were prepared in the field by MZB personnel. External measurements were taken in the field with a ruler (head-body, tail, hindfoot, and ear lengths) and Pesola scales graduated to $1 \mathrm{~g}$ (body mass).

\section{Morphological description}

We used qualitative morphological (external, cranial and dental) characters and morphometric analysis to document morphological similarities and differences in individuals and species. Specimens examined for this study are stored at the Australian Museum, Sydney, Australia (AM); American Museum of Natural History, New York, USA (AMNH); the Natural History Museum, London, UK (BMNH); the Museum Zoologicum Bogoriense, LIPI, Cibinong, Indonesia (MZB); and the National Museum of Natural History, Smithonian Institution, Washington, D.C., USA (USNM). A list of museum specimens used as comparative material is provided in Supplemental Appendix 1. All Melomys burtoni specimens from Halmahera are stored 

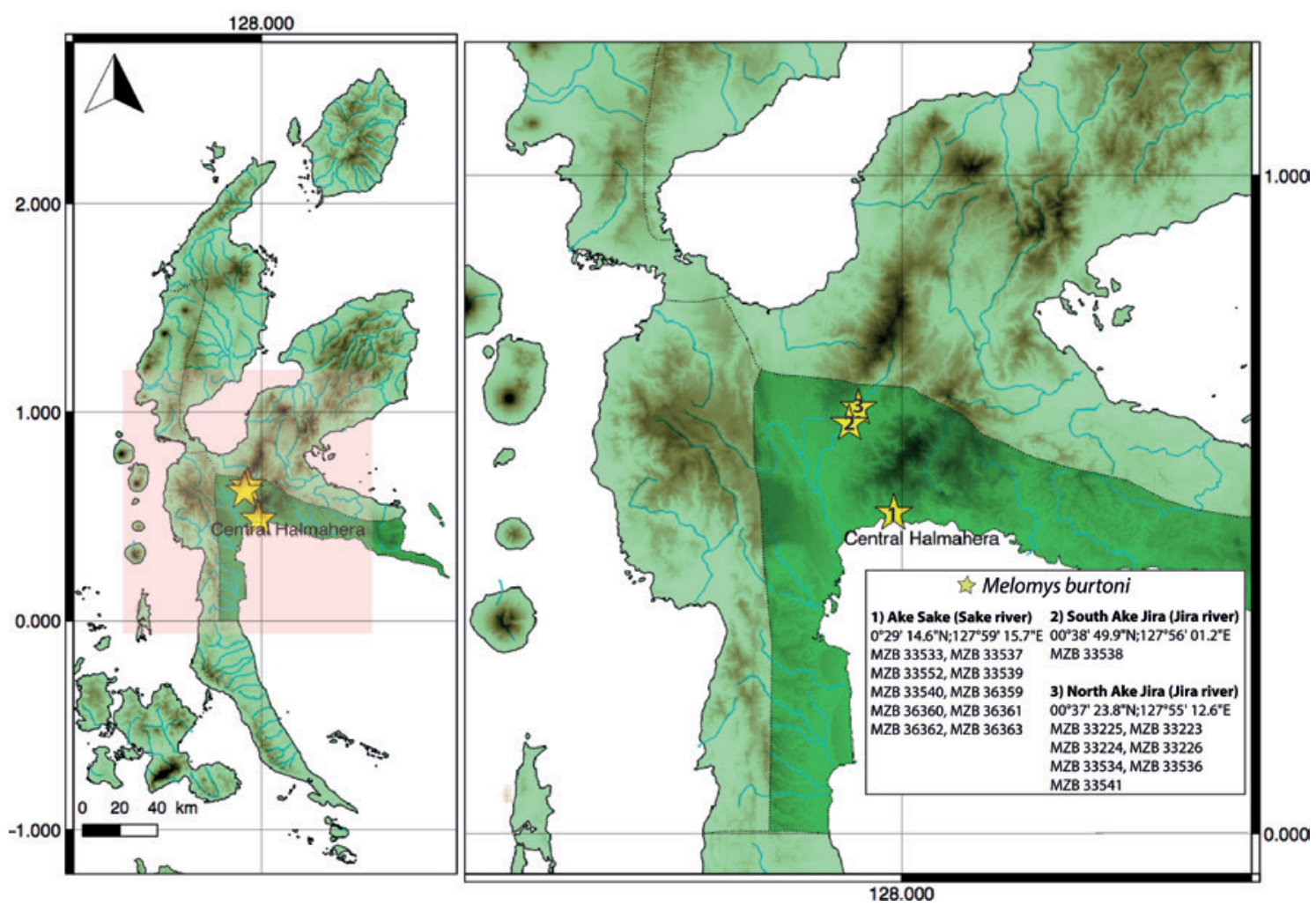

Figure 1: Map of central Halmahera, showing the localities for Melomys burtoni, represented by a star. Collection localities are: (1) Ake Sake, (2) South Ake Jira; (3) North Ake Sake. Field (WD) and voucher (MZB) numbers are indicated in the lower right side of the maps. Maps are modelised using the SRTM open database (http://www.cgiar-csi.org/data/srtm-90m-digital-elevation-database-v4-1) in the open source QGIS software (http://www.qgis.org/en/site/index.html).

at the Museum Zoologicum Bogoriense, LIPI, Cibinong, Indonesia (MZB).

The skulls of the Melomys burtoni from Halmahera were photographed with a digital camera stored in the Zoological Museum of the University of Copenhagen (ZMUC), Denmark, and imaged with a $\mu \mathrm{CT}$ scanner stored at the Plateforme Microtomographie, in Montpellier University, France.

Measurements of head-body length (HB), tail length (TL), hind foot length (including claws) (HF), ear length (from notch) (E), and body mass in grams (WT) were taken from field catalogs, and tags associated with museum specimens, as recorded by the authors in the field. For our craniometric comparisons, 22 cranial and dental features were measured. Only adults with complete skulls were measured. Specimens were judged to be adult by ossification of the cranial synchondrosis between the basioccipital and basisphenoid (the "basilar suture"), possession of fully erupted molars displaying at least moderate wear, and adult pelage. Using a dial caliper graduated to 0.01 , we measured the following craniodental dimensions, defined and illustrated by Musser and Newcomb (1983): greatest length of the skull (GLS); least interorbital breadth (IB); greatest zygomatic breadth (ZB); length of the rostrum
(LR); breadth of the rostrum (BR); breadth of the braincase (BBC); height of the braincase (HBC); breadth of the zygomatic plate (BZP); length of the diastema (LD); postpalatal length (PPL); length of the bony palate (LBP); breadth of the bony palate at first molar (BBPM1); breadth of the bony palate at third molar (BBPM3); length of incisive (anterior palatal) foramina (LIF); breadth across incisive foramina (BIF); length of auditory bulla (LB); crown length of maxillary molar row (CLM1-3); crown length of dentary molar row (clm1-3); breadth of first upper molar (BM1); breadth of first lower molar (bm1); breadth of second lower molar (bm2); breadth of third lower molar (bm3). We used the statistical software program R version 2.15 (R Development Core Team 2012) to calculate descriptive (mean, standard deviation, observed range). Melomys samples from the Moluccas were small because very few specimens have been collected and deposited in world museums.

\section{Molecular biology and genetic analysis}

Ethanol-preserved tissue samples for Melomys burtoni from Halmahera and Melomys paveli were obtained from 
the MZB mammal tissue collection. Total DNA extractions were performed using the QIAamp DNA mini kit (Qiagen, Crawley, UK). Fragments from one mitochondrial gene, $16 S r R N A$, and two nuclear introns, acid phosphatase type $\mathrm{V}$ (AP5) and dihydrofolate reductase (DHFR), were amplified and sequenced using the following primers: (1) for $16 S$ rRNA (Palumbi et al. 1991): 16AR (5' - CGCCTGTTTAACAAAAACAT - 3') and 16BR (5' - CCGGTTTGAACTCAGATCACG T - 3'), (2) for AP5 (DeBry and Seshadri 2001): AP5 120F (5' - AATGCCCCATTCCACACAGC - 3') and AP5 564R (5' - GCAGAGACGTTGCCAAGG TG - 3'), and (3) for DHFR (Lyons et al. 1997): DHFR intron F ( $5^{\prime}$ - ATCGTCGCCGTGTCCC $\left.-3^{\prime}\right)$ and DHFR intron R $\left(5^{\prime}-\right.$ TGAGGTTGTGGTCATTCTTTGG - 3'). We selected these molecular markers (16S RNA, AP5, DHFR) to use existing data (Bryant et al. 2011) and to place the new taxon in a phylogenetic context. PCR conditions were the same for all the sequenced genes: $95^{\circ} \mathrm{C} 5 \mathrm{~min}$, followed by $95^{\circ} \mathrm{C} 30 \mathrm{~s}, 61^{\circ} \mathrm{C} 30 \mathrm{~s}, 72^{\circ} \mathrm{C} 1 \mathrm{~min}$ ( 5 times), then $95^{\circ} \mathrm{C} 30 \mathrm{~s}, 59^{\circ} \mathrm{C} 30 \mathrm{~s}, 72^{\circ} \mathrm{C} 1 \mathrm{~min}(5$ times), followed by $95^{\circ} \mathrm{C} 30 \mathrm{~s}, 57^{\circ} \mathrm{C} 30 \mathrm{~s}, 72^{\circ} \mathrm{C} 1 \mathrm{~min}\left(5\right.$ times), then $95^{\circ} \mathrm{C} 30 \mathrm{~s}$, $55^{\circ} \mathrm{C} 30 \mathrm{~s}, 72^{\circ} \mathrm{C} 1 \mathrm{~min}\left(5\right.$ times), and then $95^{\circ} \mathrm{C} 30 \mathrm{~s}, 53^{\circ} \mathrm{C}$ $30 \mathrm{~s}, 72^{\circ} \mathrm{C} 1 \mathrm{~min}$ (20 times), with a final extension at $72^{\circ} \mathrm{C}$ 5 min. PCR products for all genes were purified from $1 \%$ agarose gel using Amicon Ultrafree-DNA columns (Millipore) and sequenced on both strands using automatic sequencing (Big Dye Terminator cycle kit) on an ABI 310 (PE Applied Biosystems, Foster City, CA, USA). No ambiguity was found in the mitochondrial 16S rRNA. Considering the nuclear genes, we found respectively 3 and 9 ambiguities for AP5 and DHFR, that were subsequently coded as S, Y or M. As we only have 11 sequenced individuals for AP5 and eight individuals for DHFR, it was not possible to obtain mutation phasing in order to recover the alleles. We combined the newly obtained sequences with the Melomys/Paramelomys DNA matrices of Bryant et al. (2011). Bryant et al. (2011) incorporated 7 of the 23 extant species of Melomys recognized by Musser and Carleton (2005), and also included the closely-related genus Solomys (Rowe et al. 2008; Bryant et al. 2011). Our analyses added two taxa, M. burtoni from Halmahera and M. paveli (Helgen 2003; the latter recently collected for the second time in Seram by P.-H. Fabre). We included species of Paramelomys and Uromys as relevant closely-related outgroups, and representatives of Rattus and Pogonomys as more distant outgroups (Rowe et al. 2008). Sequences were aligned with MAFFT (Katoh and Toh 2010) and the ED editor of the MUST package (Philippe 1993). From these individual alignments, we built one matrice with nuclear + mitochondrial (98 taxa and 1160 sites) sequences, respectively, where gap were coded as missing data. Phylogenetic trees were reconstructed using maximum likelihood (ML) and Bayesian inference approaches for the three-gene concatenated dataset. Modeltest 3.07 (Posada and Crandall 1998) was used to determine the best-fit ML model of DNA sequence evolution under the Akaike information criterion (AIC). ML parameters and topologies were estimated by PAUP^ version 4 b10 (Swofford 2002) using a loop approach. The ML parameter values were first optimized on a Neighbor-Joining (NJ) topology generated from ML distances obtained using the best-fit model. A ML heuristic search was subsequently applied with tree bisection-reconnection (TBR) branch-swapping to identify the optimal topology. The highest likelihood parameter values were re-estimated on this new topology. A new heuristic tree search was run under these new parameters. The loop procedure was performed until stabilization of both topology and parameters were achieved in these analyses. The robustness of nodes was estimated by ML bootstrap percentages after 100 replicates using previously estimated parameters, the NJ starting tree, and the TBR branch swapping tree. To account for differences in DNA substitution patterns among genes, we applied a Bayesian model-partitioned strategy for the analyses of the three supermatrices. MrBayes 3.1.2 (Ronquist and Huelsenbeck 2003) was used for these analyses, as it allows different models of evolution for each gene partition. Best-fit models for the Bayesian analyses were identified using Modeltest, and those with the highest AIC were implemented. All parameters except topology were unlinked across partitions and two independent runs using Markov chain Monte Carlo (MCMC) approaches were computed simultaneously, each with one cold and three heated chains. The MrBayes analyses were run for $50 \times 10^{7}$ generations, with sampling every 1000 generations. In all cases, stability of log-likelihood and model parameters was reached by the end of the analysis. Majority rule consensus trees were constructed after a burn-in of $5 \times 10^{5}$ generations. Clade support was calculated by posterior probabilities.

The topologies found in the analyses, as well as alternative phylogenetic hypotheses derived from previous taxonomic/morphological hypotheses, were tested under the nuclear + mitochondrial supermatrix using the approximately unbiased test (AU - Shimodaira 2002) as implemented in CONSEL (Shimodaira and Hasegawa 2001). PAUP* version $4.0 \mathrm{~b} 10$ (Swofford 2002) was used to calculate the site likelihoods for each of the test topologies with each gene partitioning scheme implemented, in addition to the appropriate model for each partition specified using the output from Modeltest. The CONSEL 
analyses employed 10 batches of $10^{7}$ bootstrap replicates. Using PAUP, we enforced the monophyly of (1) Melomys burtoni from Halmahera, (2) M. burtoni and (3) M. lutillus. The resulting topologies were employed to test alternative topologies. All new sequences were deposited in GENBANK (GB303661-GB303696, Table 1).

\section{Geometric morphometric procedures}

To explore the variability in skull form, 151 specimens from 17 species were photographed from previously cited museums from the palatal view for geometric morphometrics analyses (see Supplemental Appendix 2 for a detail list of the specimens). We carefully checked skin and skull specimens to verify their identification, age and geography. Dental abrasion and cranial ossification patterns were used to identify juveniles. Landmark coordinate were taken from the palatal view of the specimens and was described by 43 landmarks (Figure 2). We measured two additional points, spaced by $1 \mathrm{~cm}$ from each other on a millimetre scale and photographed along with the skull, and used it for scaling objects. A CANON 7D video camera equipped with a macro-lens EF $100 \mathrm{~mm} \mathrm{f} / 2.8 \mathrm{~L}$ as well as the software TPS dig2 (Rohlf 2013) was used to get the $\mathrm{x}$ and y coordinates of each landmark. We tested repeatability using a PCA on 30 repetitions of three specimens from the same species and population. Variation of repetitions undergone on the same specimen was much lower than the inter-individual variation, indicating the validity of our approach.

We subsequently implemented geometric morphometric methodologies (Bookstein 1991, Slice 2007) to provide a description of the shape of the palatal view and locating the areas that display shape variation and that separate different Melomys species. Palatal landmarks were analyzed with a general procrustean analysis (GPA, Rohlf and Slice 1990). This method consists of a superimposition, normalization of size and rotation to generate residual size-free data. The logarithm of the centroid size was employed as an indicator of size and subsequently used in our analyses. As superimposed coordinates are redundant (Dryden and Mardia 1998), a PCA was computed on it, and the 2 (dimensions) by 33 (landmarks) minus 4 (lost degrees of freedom) PCs were considered for multivariate analyses of variance. To visualize the pattern of shape variation observed on the two main PC axes, we computed extreme morphologies along each PC from Procruste data. An univariate linear model on centroid size was employed to test the potential effects of species and sex. A multivariate linear model was also applied on the PCs of shape variation using non-zero eigenvalues (10 first axes). The sex and species factors, the size variable, as well as the interactions until the third order, were took into account as explanatory variables. Univariate (for size) and multivariate (for shape) analyses of variance were performed on the different variances explained by the covariables and factors following Claude (2013) methodology. We also performed these analyses on a full dataset and a subdataset. This subdataset take into account our phylogenetic results and comprised two Australo-Papuan species (Melomys burtoni, M. lutillus) and the Moluccan M. paveli and M. burtoni from Halmahera. On each figure, the extreme morphologies were plotted along the two first PCs for Procrustes data.

Table 1: List of Molucca Melomys specimens treated in this study and GenBank accession numbers of sequences.

\begin{tabular}{llllllll}
\hline Taxa & Field no. & Voucher & Area & Localities & 16S & AP5 & DHFR \\
\hline Melomys burtoni & WD115 & MZB 33224 & Indonesia, Halmahera & North Ake Jira & KY303661 & KY303675 & - \\
Melomys burtoni & WD140 & MZB 33225 & Indonesia, Halmahera & North Ake Jira & KY303662 & KY303676 & KY303687 \\
Melomys burtoni & WD144 & MZB 33223 & Indonesia, Halmahera & North Ake Jira & KY303663 & KY303677 & KY303688 \\
Melomys burtoni & WD551 & MZB 33541 & Indonesia, Halmahera & North Ake Jira & KY303664 & KY303678 & KY303689 \\
Melomys burtoni & WD277 & MZB 33536 & Indonesia, Halmahera & North Ake Jira & KY303665 & KY303679 & KY303690 \\
Melomys burtoni & WD148 & MZB 33226 & Indonesia, Halmahera & North Ake Jira & KY303667 & KY303681 & KY303692 \\
Melomys burtoni & WD279 & MZB 33534 & Indonesia, Halmahera & North Ake Jira & KY303673 & \\
Melomys burtoni & WD304 & MZB 33538 & Indonesia, Halmahera & South Ake Jira & KY303670 & KY303684 & KY303694 \\
Melomys burtoni & WD312 & MZB 33540 & Indonesia, Halmahera & Ake Sake & KY303666 & KY303680 & KY303691 \\
Melomys burtoni & WD283 & MZB 33537 & Indonesia, Halmahera & Ake Sake & KY303668 & KY303682 & KY303693 \\
Melomys burtoni & WD309 & MZB 33533 & Indonesia, Halmahera & Ake Sake & KY303669 & KY303683 & - \\
Melomys burtoni & WD310 & MZB 33539 & Indonesia, Halmahera & Ake Sake & KY303671 & KY303685 & - \\
Melomys burtoni & WD282 & MZB 33552 & Indonesia, Halmahera & Ake Sake & KY303672 & KY303686 & - \\
Melomys paveli & YS284 & MZB 35961 & Indonesia, Seram & Gunung Manusela & KY303674 & - & KY303696 \\
\hline
\end{tabular}




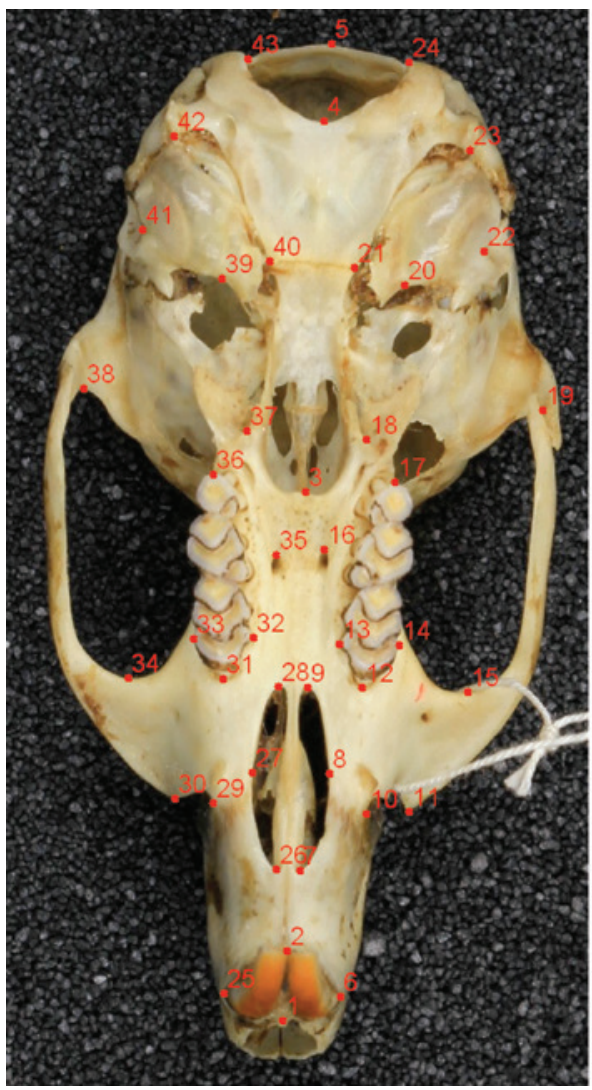

Landmarks used for the geometric morphometrics analysis:

1: Middle-Front level of the incisors placed on the premaxillary

2: Tip-junction of the incisors

3: Mid-most -posterior point of the palatal bone

4: Mid-most- anterior point of the foramen magnum

5: Mid-most-posterior point of the foramen magnum

(Rigth-Left Landmarks)

6-25: Most lateral point of the incisor

7-26: Most anterior point of the incisive foramina

8-27: Most lateral point of the incisive foramina

9-28: Most posterior point of the incisive foramina

10-29: Maxillar insertion of the zygomatic root

11-30: Most anterior point of the zygomatic plate

12-31: Most anterior point of the first upper molar

13-32: Most lingual point of the first lamina of the upper molar 1

14-33: Most labial point of the first lamina of the upper molar 1

15-34: Most anterior point of the temporal fossa

16-35: Most posterior point of the posterior palatine foramina

17-36: Most postero-lateral point of the third upper molar

18-37: Most anterior point of the spheno-pterygoid fossa

19-38: Most posterior point of the temporal fossa

20-39: Junction between bulla tympanica and eustachian tube

21-40: Junction between basioccipital and basisphenoid

22-41: Most internal point of the external auditory meatus

23-42: Contact between bulla tympanica and jugular process

24-43: Mid-Lateral point of the foramen magnum

Figure 2: Landmark locations and definitions on the palatine view of the Melomys skull.

\section{Results}

\section{Genetic analyses}

We present the most likely topology in Figure 3. The best maximum likelihood topology and node support (bootstrap and posterior probabilities) for the supermatrix can be seen in Figure 3. We recovered a broad scale topology similar to that of Bryant et al. (2011), so we will not describe the full context of phylogenetic relationships within Melomys. Instead, we focus on the phylogenetic relationship of $M$. burtoni from Halmahera compared to its closest relatives. The mitochondrial-nuclear DNA tree recovered a clade comprising $M$. burtoni (Ramsay 1887) from Australia, M. lutillus (Thomas 1913) from New Guinea, M. paveli from Seram, and M. burtoni from Halmahera (bootstrap $=75 \%$ and $\mathrm{PP}=1$ ). Within this group, there is only low level molecular divergence in our compared loci (16S: 434 constant character and 12 parsimonyinformative characters; AP5: 353 constant characters and three parsimony-informative characters; DHFR: 334 constant characters and seven parsimony-informative characters). Not surprisingly, no support was obtained for the monophyly of any single species including $M$. burtoni from Halmahera. However, monophyly could not be rejected for samples of $M$. burtoni from Halmahera (AU test; $\mathrm{p}>0.1$ ), M. lutillus (AU test; $\mathrm{p}>0.1$ ), or M. burtoni (AU test; $\mathrm{p}>0.1$ ). Further gene sampling will be required in order to elucidate the precise relationships and taxomic status of $M$. burtoni population from Halmahera with regard to its candidate sister taxa and populations.

\section{Geometric morphometric procedures}

Principal components analysis was performed on superimposed coordinates of both full (Figure 4) and subset (Figure 5) datasets. The projection of individuals for the full dataset (Figure 4) shows that species are well distinguished along PC 1, which represents a shorter incisive foramina, narrower skull, smaller tympanic bulla, and narrower zygomatic plate for three Papuan species (Melomys dollmani, M. leucogaster, M. rufescens), and three South Moluccan species (M. aerosus, M. fulgens, M. paveli) as well as two North Moluccan species (M. caurinus, M. obiensis). The Australo-Papuan and Moluccan Melomys (M. burtoni, M. cervinipes, M. cooperae, M. fraterculus, M. frigicolla, 


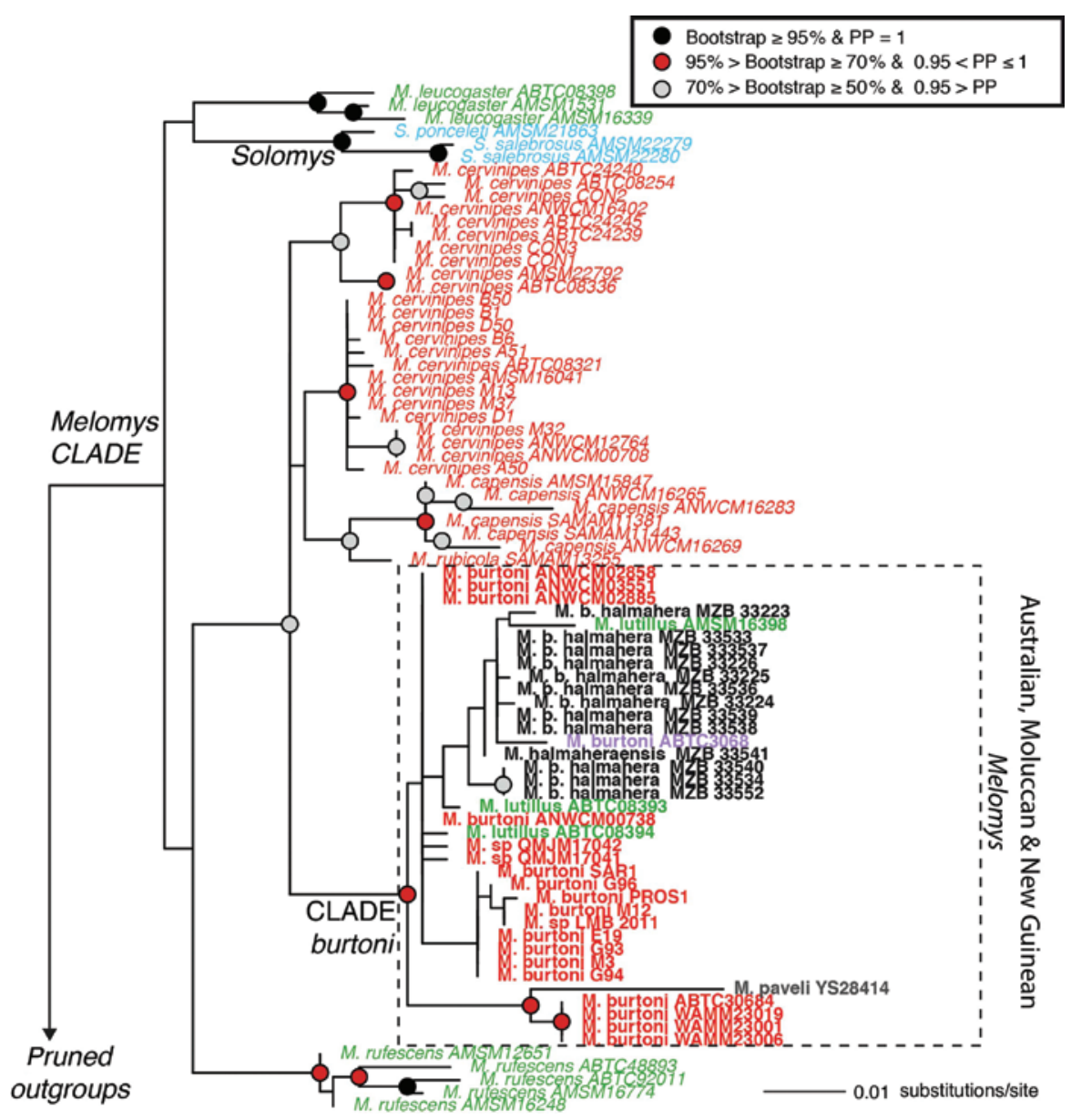

Figure 3: Best maximum-likelihood topology for Melomys produced from the combined analysis. Labeled clades are discussed in the text. Symbols at nodes represent maximum likelihood (ML) bootstrap support values $>70 \%$ and Bayesian posterior probabilities $(P P)>0.95$. Voucher numbers are indicated for each specimen used in this study. The outgroups as well as distant relatives of the Moluccan Melomys species were pruned. Circles at nodes represent bootstrap support (circles: blackbootstrap $\geq 95 \%$ and $\mathrm{PP}=1$; red $95 \%>$ bootstrap $\geq 70 \%$ and $0.95<\mathrm{PP} \leq 1$; gray $70 \%>$ bootstrap $\geq 50 \%$ and $0.95>\mathrm{PP}$ ). Legends of the colour names: Red $=$ Australia, green $=$ Papua, black $=$ North Moluccas, blue $=$ Solomons, gray $=$ South Moluccas.

M. howi, M. lutillus, and M. burtoni from Halmahera) also group together, consistent with our molecular analyses. These species share a larger skull and tympanic bulla and shorter incisive foramina. On PC2, species are separated by rostrum length, molar row length, and incisive foramina length; this axis appears to show intra-specific differentiation (Figure 4), likely due to strong allometric relationships that differ between species (see subsequent statistical analyses). When we restricted the analysis to only closely related Australian and Halmaheran $M$. burtoni, M. lutillus, and M. paveli, we found that Halmaran $M$. burtoni occupied a slightly distinct morphospace compared to M. lutillus, and M. paveli, and Australian M. burtoni. On PC2, Halmaheran M. burtoni are characterized by a longer rostrum, longer incisors also, shorter molar row and narrower skull. Using this second PC axis, Halmaheran $M$. burtoni can be differentiated from other closely related Melomys species based on longer incisive foramina that extend beyond the first molar and reach anteriorly to near the incisor tip, a narrower skull and longer distance between the third molar 3 and pterygoid fossa landmarks.

Species significantly differed in skull centroid size [full and subset data analysis of variance (ANOVA), Table 2] and skull shape significantly varied by species, size, and sex with significant interactions between size and species, and sex and species observed only in the full dataset analyses [full and subset data multivariate analysis of variance (MANOVA), Table 3].

\section{Taxonomic conclusions}

In summary, our phylogenetic analyses indicate that Halmaheran Melomys burtonibelongs to a clade containing 
several closely-related species of small Melomys ( $M$. burtoni, M. lutillus, and M. paveli; clade burtoni; Figures 3, $5-7)$ and that each of these species is at an early stage of genetic divergence from a common ancestor. However, we note that the relatively conservative molecular markers we employed are not ideal for studying the evolution of a group of species that have undergone such a rapid evolutionary diversification.

Previous accounts of Melomys have informally referred to a "Melomys lutillus" group (cf. Flannery 1995a,b) but we prefer the label M. burtoni group, after the earliest named member of this assemblage. Various species not yet sampled in molecular phylogenetic comparisons may also belong in this group, including M. bannisteri of the Kai Islands, $M$. howi of the Tanimbar Islands, M. frigicola of montane New Guinea, M. obiensis of the North Moluccan islands of Obi and Bisa, one or more Melomys populations from the Louisiade Archipelago of
Southeastern Papua New Guinea (Flannery 1995a, Musser and Carleton 2005), and possibly other enigmatic Moluccan taxa of uncertain affinity (such as $M$. aerosus and $M$. fraterculus of Seram). These small-bodied species differ notably in size, colour, and external and craniodental proportions (Tate 1951). A comprehensive understanding of the taxonomic boundaries and relationships within these island species will require additional molecular comparisons, with greater taxonomic sampling and faster evolving genetic markers. Based on the current evidence that geometric morphometrics (see Figure 5), biogeographical location (Figure 1), and genetic comparisons (Figure 3), we cannot describe the Halmaheran Melomys burtoni as a new insular species. Instead we describe its morphology and variation in the subsequent part and place it within the $M$. burtoni species group, a group that awaits a proper revision. This description will set a basis for a potential species rank elevation.
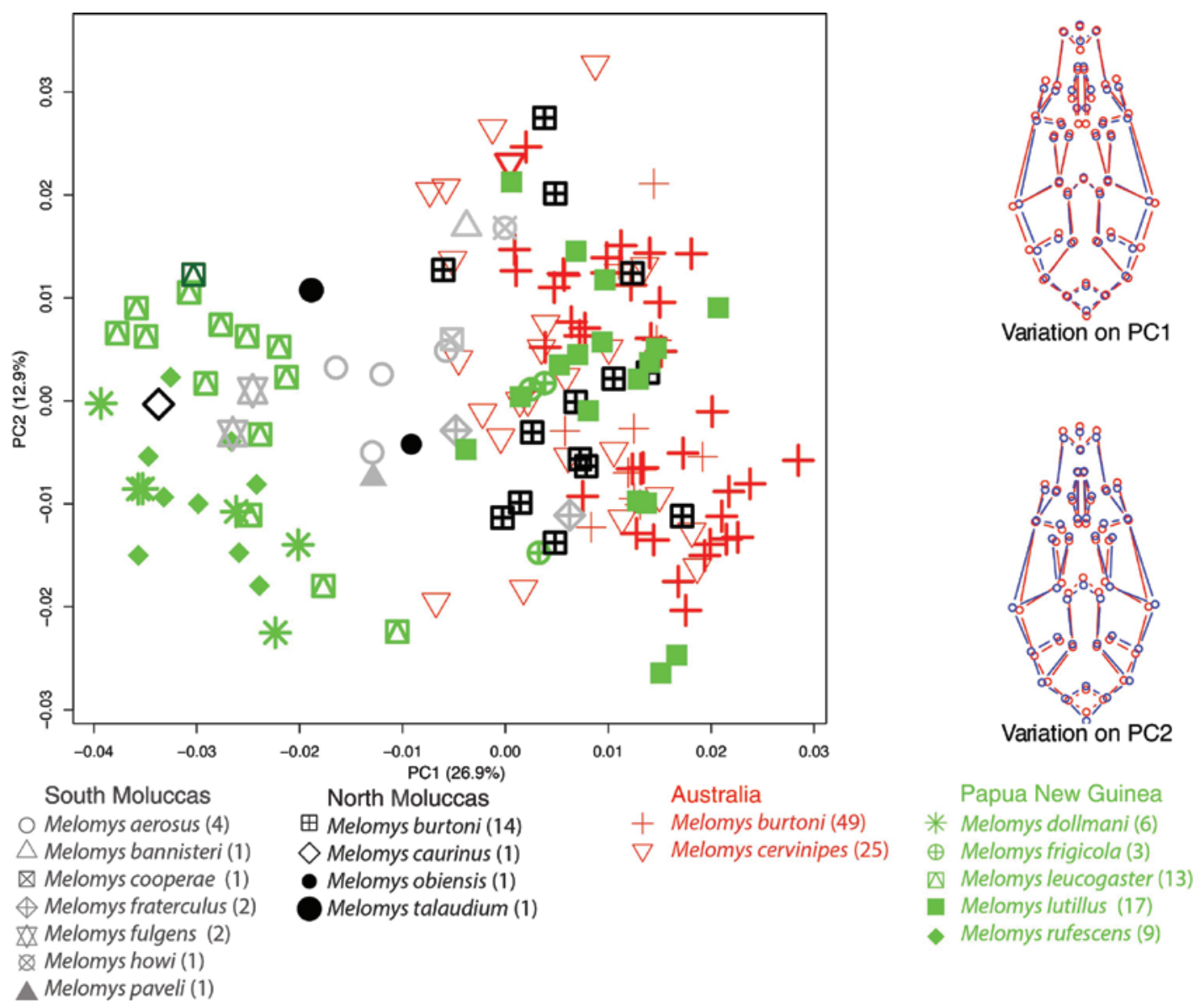

Figure 4: PCA on Procrustes coordinates for the 17 Melomys species dataset, similar symbols and colors of Figure 3. Patterns of shape variation along PC1 and PC2 are illustrated on the right side of the graphic, blue corresponding to minimal scores, red to maximal ones. Bold and thin outline represent, respectively, males and females. Red $=$ Australia, green $=$ Papua, black $=$ North Moluccas, gray $=$ South Moluccas. 


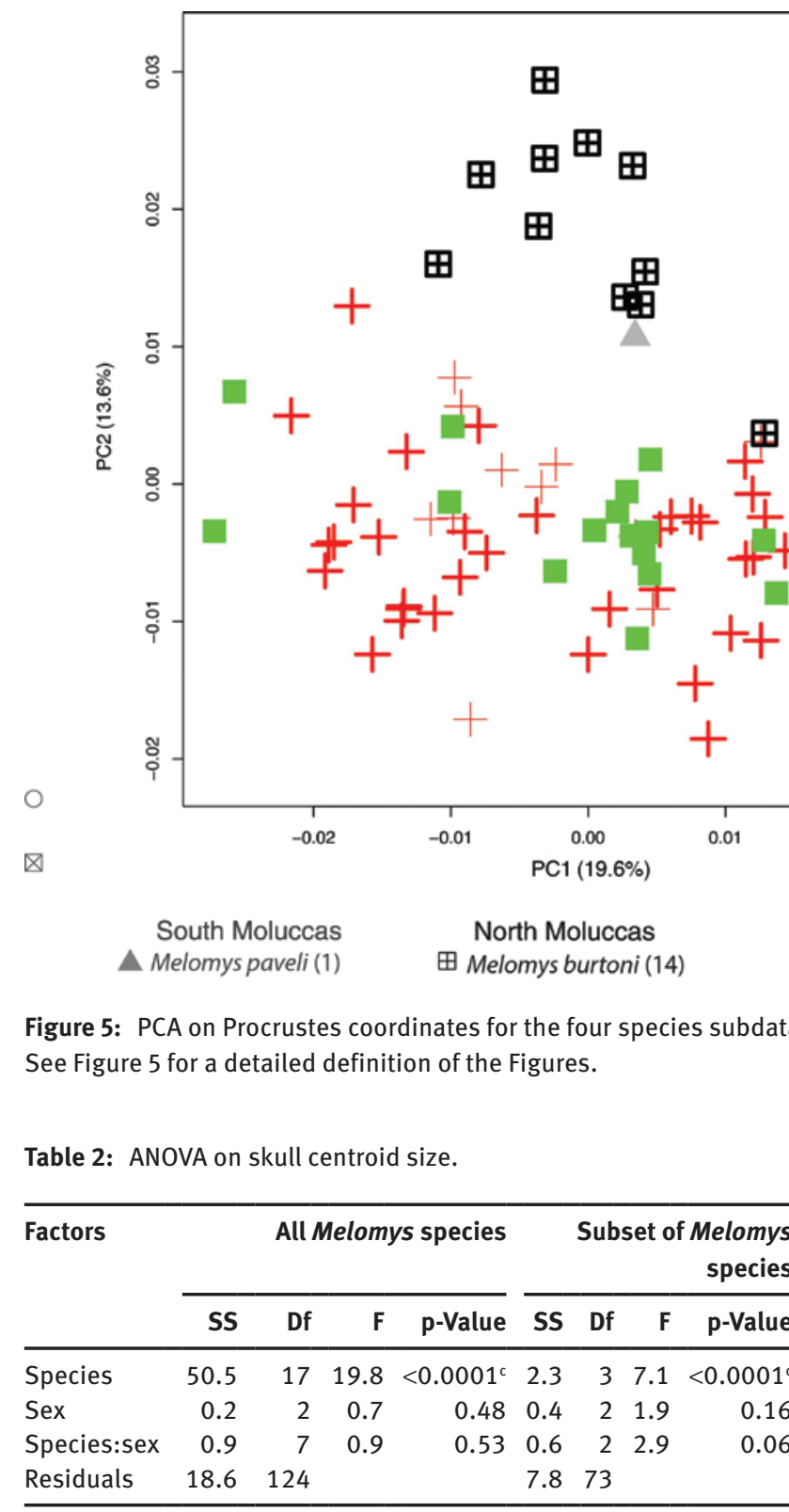

$p=p$-value. $\left({ }^{c} p<0.001\right)$. Df, degree of freedom. F, F statistic provided by $R$. The symbols “:” indicates tested interactions between explanatory variables.

\section{Systematics}

\section{Melomys Thomas 1922a}

\section{Type species}

Melomys rufescens (Alston 1877), by original designation.

\section{Diagnosis}

Melomys is a murid genus classified in the subfamily Murinae (sensu Musser and Carleton 2005), within the tribe Hydromyini (Aplin and Helgen 2010), in the "Uromys

Table 3: MANOVA on the first shape principal components for skull Procrustes data.

\begin{tabular}{|c|c|c|c|c|c|c|c|c|c|c|c|c|}
\hline \multirow[t]{2}{*}{ Factors } & \multicolumn{6}{|c|}{ All Melomys species } & \multicolumn{6}{|c|}{ Subset of Melomys species } \\
\hline & Df & Pillai & Approx. F & Num. df & Den. df & p-Value & Df & Pillai & Approx. F & Num. df & Den. df & p-Value \\
\hline Species & 17 & 6.72 & 2.84 & 391 & 1700 & $<0.0001^{\mathrm{b}}$ & 3 & 3 & 2.20 & 5.66 & 69 & $<0.0001^{b}$ \\
\hline Size & 1 & 0.79 & 13.59 & 23 & 84 & $<0.0001^{\mathrm{b}}$ & 1 & 1 & 0.89 & 16.28 & 23 & $<0.0001^{\mathrm{b}}$ \\
\hline Sex & 2 & 0.68 & 1.91 & 46 & 170 & $<0.002^{\mathrm{b}}$ & 2 & 2 & 0.88 & 1.56 & 46 & $0.03^{\circ}$ \\
\hline Species:size & 10 & 2.29 & 1.20 & 230 & 930 & $<0.04^{\mathrm{a}}$ & 1 & 2 & 0.84 & 1.44 & 46 & 0.07 \\
\hline Species:sex & 7 & 1.81 & 1.36 & 161 & 630 & $<0.005^{b}$ & 2 & 2 & 0.79 & 1.31 & 46 & 0.14 \\
\hline Size:sex & 1 & 0.36 & 2.09 & 23 & 84 & $<0.008^{b}$ & 2 & 1 & 0.23 & 0.58 & 23 & 0.92 \\
\hline Species:size:sex & 6 & 1.24 & 1.01 & 138 & 534 & 0.45 & 1 & 2 & 0.51 & 0.69 & 46 & 0.91 \\
\hline
\end{tabular}

Legend similar to that of Table 1. The symbol “:” indicates tested interactions between explanatory variables. $\left({ }^{a} p<0.05,{ }^{b} p<0.01\right)$. 


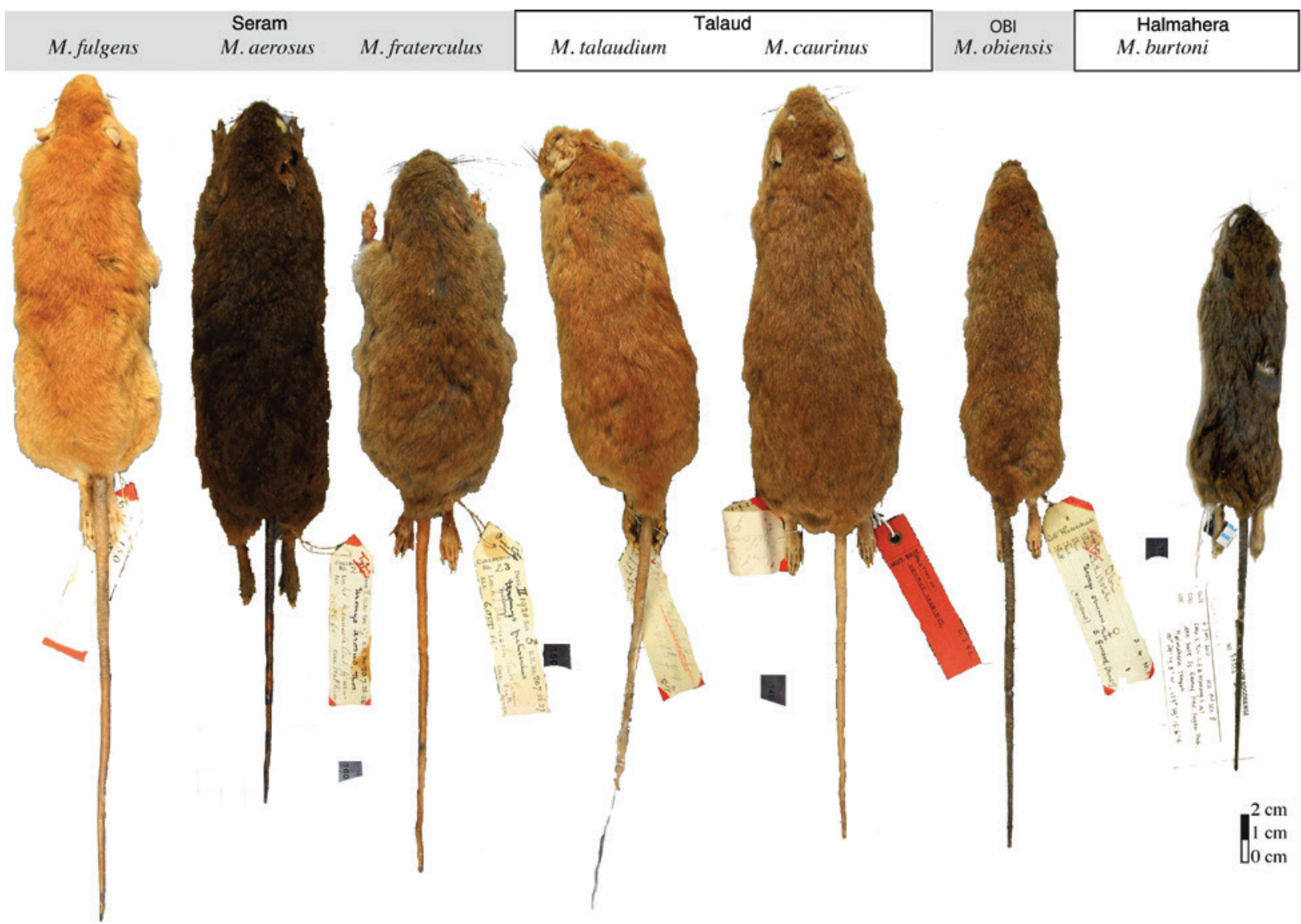

Figure 6: Dorsal view of study skins representing six Melomys species.

From right to left: $M$. fulgens (Seram, BMNH 20.7.26.19), $M$ aerosus (Seram, BMNH 20.7.26.21), M. fraterculus (Seram, BMNH 20.7.26.27), Melomys paveli (Seram MZB 35961), M. talaudium (Pulau Lirung (= Salibabu), Talaud, BMNH. 2.2.9.3), M. caurinus (Talaud, BMNH 12.2.9.3), M. obiensis (Obi, AM M24392) and M. burtoni (Halmahera, MZB 33552). Scale bar $012 \mathrm{~cm}$.

Division” of Musser and Carleton (2005). Species within this genus are small to medium-sized (HB max $190 \mathrm{~mm}$ ) and are characterized by external characters (Tables 4 and 5) including (1) raised tail scales, (2) one or three short hairs per tail scale, (3) a broad hindfoot, and (4) a long first hindfoot digit reaching the origin of digits 2-4. To diagnose this genus Menzies (1996) used the following set of craniodental characters: (1) broad skull with a convex profile, (2) a palate terminating before the posterior end of the molar row, (3) a zygomatic plate sloping forward at the shoulder, (4) nasal bones that do not significantly extend past the premaxillae, (5) large auditory bullae compared to species of Paramelomys (cf. Menzies 1996), (6) narrow and deep pterygoid fossae, (7) lateral extension of the parietal bone, (8) a wide alisphenoid strut that is fused to the alisphenoid canal and foramen ovale, (9) very well-developed lambdoid crests which curl forward over the squamoso-mastoid foramen, (10) a carotid arterial circulation that is primitive for murine rodents, as opposed to the derived pattern seen in Mammelomys (11) a large
$\mathrm{M}^{3}$ compared to Paramelomys, with an antero-internal cusp always present, and (12) only two pairs of inguinal teats (mammary formula $0+2=4$ ). The Melomys population from Halmahera is characterized by small to medium body size in the genus (Weight range $=110-141 \mathrm{~g}$ ), and has all of the diagnostic characters listed above.

Content and distribution. The genus Melomys contains 23 species (Musser and Carleton 2005). It is distributed in eastern and northern Australia, throughout New Guinea, and in adjacent archipelagos, from the Moluccas in the west to the Solomon Islands in the east (Helgen 2003, Breed and Aplin 2008).

\section{Melomys burtoni from Halmahera}

\section{Referred specimens}

Ten specimens of Melomys burtoni from Halmahera were caught near the Gemaf and Sagea villages on June 2010 and September 2013 (MZB 33533, 33537, 33539, 33540, 


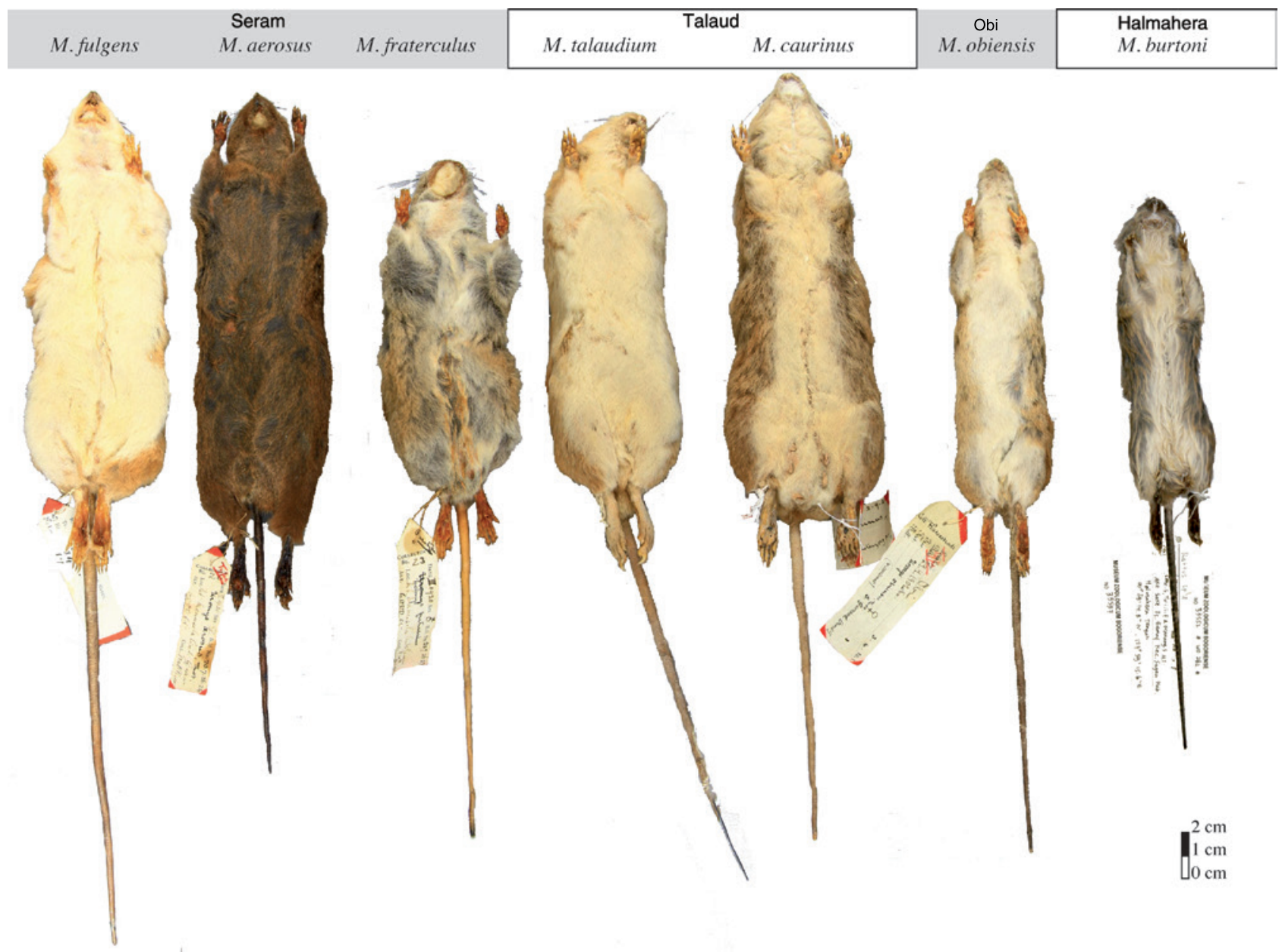

Figure 7: Ventral view of study skins representing six Melomys species.

From right to left: $M$. fulgens (Seram, BMNH 20.7.26.19), M. aerosus (Seram, BMNH 20.7.26.21), M. fraterculus (Seram, BMNH.20.7.26.27), M. paveli (Seram MZB 35961), M. talaudium (Pulau Lirung (=Salibabu), Talaud, BMNH.12.2.9.3), M. caurinus (Talaud, BMNH.12.2.9.3), M. obiensis (Obi, AM M24392) and M. burtoni (Halmahera, MZB 33552). Scale bar $012 \mathrm{~cm}$.

$33225,36359,36360,36361,36362,36363)$, and eight specimens were collected on the South (MZB 33538) and North Ake Jira (Sake River; MZB 33223, 33224, 33226, 33534, 33536, 33541, 33552) in January 2010, 19 km NW of Gemaf and 26 $\mathrm{km}$ NW of Sagea at the GPS coordinates $00^{\circ} 37^{\prime} 23.8^{\prime \prime} \mathrm{N}$, $127^{\circ} 55^{\prime} 12.6^{\prime \prime} \mathrm{E}$ (South Ake Jira) and $00^{\circ} 38^{\prime} 49.9^{\prime \prime} \mathrm{N}$, $127^{\circ} 56^{\prime} 01.2^{\prime \prime} \mathrm{E}$ (North Ake Jira); Ake Sake (Sake River), $5 \mathrm{~km}$ NW of the village of Gemaf and $12 \mathrm{~km}$ NW of the village of Sagea, Central Halmahera, Halmahera Island, Indonesia, at an altitude of $22 \mathrm{~m}$, at the GPS coordinates $00^{\circ} 29^{\prime} 14.6^{\prime \prime} \mathrm{N}$, $127^{\circ} 59^{\prime} 15.7^{\prime \prime} \mathrm{E}$ (see Figure 1). Their current altitudinal range is 0 from $250 \mathrm{~m}$. Seventeen specimens are prepared as study skins with accompanying skulls.

\section{Distribution}

Currently, Melomys burtoni from Halmahera is known only from the south-central region of the North Moluccan island of Halmahera (Figure 1). The species has been collected in lowland forest and forest edge habitats, at elevations between 0 and $250 \mathrm{~m}$. We suspect that it may occur more broadly in other regions in the tropical lowland evergreen rain forest (Whitmore et al. 1984) in Halmahera, and on neighbouring islands such as Morotai and perhaps Bacan, but little is yet known of its biology and distribution. Previous efforts to survey the rodent fauna of Halmahera and adjacent islands (specimens deposited at AM, AMNH, MZB, USNM), which have documented two native rodent species (Rattus morotaiensis and Halmaheramys bokimekot) and several non-native rodents (Rattus exulans, $R$. tanezumi/R. rattus, and Mus), have not yet documented Melomys in other areas of Halmahera or on Morotai or Bacan. However, rodent collecting efforts in the North Moluccas have been very limited to date. Sampling was done at higher elevation in Halmahera by us (9001000 m, cf. boki mekot locality Fabre et al. 2013) and also 
Table 4: Selected external and cranial measurements $(\mathrm{mm})$ and body mass (g) of adult Melomys burtoni from Halmahera and Moluccan species of Melomys (M. obiensis) as well as related Australo-Papuan species (M. frigicola, M. lutillus, M. burtoni) (means, measurement ranges, and sample sizes provided).

\begin{tabular}{|c|c|c|c|c|c|}
\hline & $\begin{array}{r}\text { Halmahera } \\
\text { burtoni }{ }^{\mathrm{a}}\end{array}$ & $\begin{array}{l}\text { Obi, Bisa } \\
\text { obiensis }^{\mathrm{b}}\end{array}$ & $\begin{array}{l}\text { Montane New Guinea } \\
\text { frigicolac }^{c}\end{array}$ & $\begin{array}{l}\text { Lowland New Guinea } \\
\text { lutillus }^{\mathrm{d}}\end{array}$ & $\begin{array}{l}\text { Australia } \\
\text { burtonie }^{\mathrm{e}}\end{array}$ \\
\hline \multirow[t]{2}{*}{$\mathrm{HBL}$} & 117 & 127 & 118 & 110 & 104 \\
\hline & $110-141(13)$ & $123-129(3)$ & $237-267(18)$ & $190-246(23)$ & $174-243(21)$ \\
\hline \multirow[t]{2}{*}{ Tail length } & 121 & 162 & 129 & 110 & 111 \\
\hline & $110-140(13)$ & $148-175(2)$ & $122-136(18)$ & $85-135(23)$ & $90-122(21)$ \\
\hline \multirow[t]{2}{*}{ Hindfoot length } & 24 & 28 & 26 & 24 & 23 \\
\hline & $20-27(13)$ & $27-29.0(4)$ & $25-28(18)$ & $23-26(23)$ & $21-25(21)$ \\
\hline \multirow[t]{2}{*}{ Ear length } & 18 & 15 & 13 & 13 & 13 \\
\hline & $15-21(13)$ & $14-17(4)$ & $12-14(18)$ & $11-14(6)$ & $12-15(21)$ \\
\hline \multirow[t]{2}{*}{ GLS } & 29.7 & 34.1 & 28.31 & 28.31 & 28.4 \\
\hline & $29.8-31.3(13)$ & $33.4-34.4(3)$ & $27.19-30.03(10)$ & $27.19-30.03(10)$ & $27.8-29.1(6)$ \\
\hline \multirow[t]{2}{*}{ ZB } & 15.6 & 17.4 & 14.26 & 14.26 & 14.2 \\
\hline & $15.1-16.3(13)$ & $17.3-17.6(3)$ & $13.6-15.19(10)$ & $13.6-15.19(10)$ & $13.8-14.21(6)$ \\
\hline \multirow[t]{2}{*}{ Mass } & 56 & 71 & NA & NA & NA \\
\hline & 37-95 (13) & $68-74(2)$ & NA & NA & NA \\
\hline
\end{tabular}

aMZB 33223-26; 33533-34; 33536-41; 33552.

'BMNH.3.4.10.1; AU 24391-92.

'AMNH 151204-215; 151217; 151223-227.

${ }^{d}$ AMNH $105754-760 ; 105762-771 ; 105866 ; 105964-965 ; 105967-969$.

eAMNH 154116; 154120; 154123; 154125-126; 154128-129; 154131; 154133; 154135; 154136-138; 154140-141; 154144; $154149-153$.

Table 5: External and cranial measurements $(\mathrm{mm})$ and body mass ( $\mathrm{g}$ ) of adult specimens of additional species of Melomys endemic to the Moluccas (means, measurement ranges, and sample sizes provided).

\begin{tabular}{|c|c|c|c|c|c|c|}
\hline & $\begin{array}{l}\text { Seram } \\
\text { paveli }^{\mathrm{a}}\end{array}$ & $\begin{array}{l}\text { Seram } \\
\text { fraterculus }^{\mathrm{b}}\end{array}$ & $\begin{array}{r}\text { Seram } \\
\text { aerosus }^{\mathrm{c}}\end{array}$ & $\begin{array}{l}\text { Seram } \\
\text { fulgens }^{\mathrm{d}}\end{array}$ & $\begin{array}{l}\text { Talaud } \\
\text { caurinus }^{\mathrm{e}}\end{array}$ & $\begin{array}{l}\text { Talauds } \\
\text { talaudium }\end{array}$ \\
\hline \multirow[t]{2}{*}{ HBL } & 124.5 & 115 & 153 & 150 & 176 & 174 \\
\hline & $123-126(2)$ & $115-115(2)$ & $150-160(5)$ & $150-150(2)$ & $176(1)$ & $173-174(2)$ \\
\hline \multirow[t]{2}{*}{ Tail length } & 133 & 154 & 132 & 203 & 137 & 171 \\
\hline & $128-138(2)$ & $153-155(2)$ & $125-138(8)$ & $200-205(2)$ & $136-137(2)$ & $150-183(3)$ \\
\hline \multirow[t]{2}{*}{ Hindfoot length } & 24 & 26 & 33 & 34 & 30 & NA \\
\hline & $22.4-26.2(2)$ & $26-26(2)$ & $31-34(8)$ & $34-34(2)$ & $30-30(2)$ & NA \\
\hline \multirow[t]{2}{*}{ Ear length } & 15 & 17.5 & 17.4 & 18 & 15 & 14.7 \\
\hline & $14.6-15.4(2)$ & $17-18(2)$ & $16-18(8)$ & $17-19(2)$ & $15(1)$ & $13-16(3)$ \\
\hline \multirow[t]{2}{*}{ GLS } & 33.6 & 32.4 & 36.6 & 39.3 & 38.6 & 38.3 \\
\hline & $33.6(1)$ & $31.7-33.0(2)$ & $35.0-37.4(7)$ & $39.3-39.4$ (2) & 38.6 (1) & $36.9-39.7(6)$ \\
\hline \multirow[t]{2}{*}{ ZB } & 15.0 & 16.1 & 18.6 & 21.1 & 20.0 & 19.6 \\
\hline & $14.7-15.3(2)$ & $15.9-16.4(2)$ & $18.0-19.8(8)$ & $20.2-22.0(2)$ & $20.0(1)$ & $18.1-20.8(6)$ \\
\hline \multirow[t]{2}{*}{ Mass } & 55 & NA & 110 & NA & NA & NA \\
\hline & $45-65(2)$ & NA & $97-123(2)$ & NA & NA & NA \\
\hline
\end{tabular}

aMZB 35961; AU 31923.

'BMNH.20.7.26.26-27.

'BMNH.20.7.26.21-25; BMNH.20.7.26.22.

${ }^{\mathrm{d}} \mathrm{BMNH}$.20.7.26.19-20.

eBMNH.21.2.9.2.

'BMNH.21.2.9.3.

other mammalogists (Flannery 1995a,b), but M. burtoni were never collected above $250 \mathrm{~m}$.

\section{Measurements}

See Tables 4-6.

\section{Diagnosis}

Melomys burtoni from Halmahera can be distinguished from congeners by the following external characters: (1) relatively small body size, e.g. as compared to $M$. aerosus and M. fulgens of Seram (Helgen 2003) (Tate 1951, Menzies 
Table 6: Cranial and dental measurements (in $\mathrm{mm}$ ) of Melomys burtoni (Halmahera).

\begin{tabular}{|c|c|c|c|c|}
\hline & \multicolumn{4}{|c|}{ M. burtoni (Halmahera) } \\
\hline & & Male $(n=6)$ & & Female $(n=6)$ \\
\hline & Mean \pm SD & Range & Mean \pm SD & Range \\
\hline GLS & $32.78 \pm 2.01$ & $(30.56 / 34.6)$ & $29.99 \pm 0.59$ & $(28.84 / 30.90)$ \\
\hline IB & $4.88 \pm 0.02$ & $(4.69 / 5.2)$ & $4.815 \pm 0.03$ & $(4.51 / 4.97)$ \\
\hline ZB & $16.37 \pm 0.51$ & $(14.96 / 17.65)$ & $14.97 \pm 0.2$ & $(14.57 / 15.84)$ \\
\hline LR & $9.42 \pm 0.06$ & $(9.14 / 9.7)$ & $8.68 \pm 0.11$ & $(8.02 / 8.93)$ \\
\hline BR & $6.01 \pm 0.09$ & $(5.40 / 6.94)$ & $5.48 \pm 0.06$ & $(5.22 / 5.92)$ \\
\hline BBC & $13.35 \pm 0.04$ & $(12.98 / 13.71)$ & $13.00 \pm 0.11$ & $(12.62 / 13.39)$ \\
\hline $\mathrm{HBC}$ & $9.66 \pm 0.01$ & $(9.51 / 9.78)$ & $9.60 \pm 0.02$ & $(9.45 / 9.78)$ \\
\hline BZP & $4.54 \pm 0.2$ & $(3.83 / 5.49)$ & $3.92 \pm 0.08$ & $(3.56 / 4.34)$ \\
\hline LD & $8.93 \pm 0.39$ & $(7.88 / 9.7)$ & $7.93 \pm 0.07$ & $(7.64 / 8.34)$ \\
\hline PPL & $11.61 \pm 0.28$ & $(10.83 / 12.58)$ & $10.08 \pm 0.36$ & $(9.09 / 10.76)$ \\
\hline LBP & $6.09 \pm 0.04$ & $(5.78 / 6.56)$ & $5.89 \pm 0.04$ & $(5.75 / 6.14)$ \\
\hline BBPM1 & $2.75 \pm 0.06$ & $(2.38 / 3.25)$ & $2.49 \pm 0.02$ & $(2.36 / 2.78)$ \\
\hline ВВРМ3 & $4.25 \pm 0.02$ & $(4.03 / 4.58)$ & $4.02 \pm 0$ & $(3.94 / 4.08)$ \\
\hline LIF & $5.82 \pm 0.01$ & $(5.53 / 6.55)$ & $5.35 \pm 0.07$ & $(5.12 / 5.85)$ \\
\hline BIF & $1.92 \pm 0.02$ & $(1.77 / 2.10)$ & $1.80 \pm 0.02$ & $(1.68 / 2.01)$ \\
\hline LB & $4.53 \pm 0.04$ & $(4.33 / 4.83)$ & $4.50 \pm 0.05$ & $(4.08 / 4.67)$ \\
\hline CLM13 & $6.03 \pm 0.03$ & $(5.84 / 6.25)$ & $5.84 \pm 0.05$ & $(5.65 / 6.15)$ \\
\hline $\operatorname{clm} 13$ & $5.79 \pm 0.10$ & $(5.64 / 6.03)$ & $5.72 \pm 0.01$ & $(5.58 / 5.90)$ \\
\hline BM1 & $1.83 \pm 0.10$ & $(1.74 / 1.98)$ & $1.77 \pm 0.10$ & $(1.68 / 1.81)$ \\
\hline bm1 & $1.68 \pm 0.10$ & $(1.61 / 1.73)$ & $1.61 \pm 0.10$ & $(1.52 / 1.71)$ \\
\hline $\mathrm{bm} 2$ & $1.92 \pm 0.10$ & $(1.89 / 1.97)$ & $1.90 \pm 0.10$ & $(1.82 / 1.93)$ \\
\hline bm3 & $1.48 \pm 0.10$ & $(1.46 / 1.51)$ & $1.43 \pm 0.10$ & $(1.39 / 1.46)$ \\
\hline
\end{tabular}

${ }^{\mathrm{a} M Z B}$ 33224-26; 33533-34; 33536-41; 33552.

1996, see also Figures 6 and 7; Tables 5 and 6); (2) headbody length is nearly equal to the tail length (103\% of the body length, but see also Figures 6 and 7) compared to the long-tailed $M$. obiensis (127 \% of the body length); (3) dorsal fur dark brown or red-brown with dark gray bases; (4) ventral fur pure white along mid-ventral region of underparts and grayish on the sides; (5) dorsal surfaces of the forefeet and hindfeet pale brown with scattered rufous hairs; (6) tail usually dark above and below (some specimens have a paler underside), with three hairs per tail scale; (7) brown ears relatively long and large.

Craniodental features diagnostic in combination include (1) a long rostrum, topped by broad nasals and slightly convex at the premaxillary tips (Figures 5, 8 and 9); (2) a narrow interorbital region with concave borders (Figure 8); (3) large palatine foramina (Figure 10), (4) long incisive foramina that extend posteriorly to the start of the molar rows (Figures 4, 5 and 10), (5) relatively longer incisive foramina and shorter tympanic bullae compared with all other species sampled here (Figures 4, 5 and 10). Following Menzies (1996), Melomys burtoni from Halmahera belongs within the "cervinipes division" and more specifically is a member of the $M$. burtoni species group that includes $M$. burtoni of Australia, M. lutillus and $M$. frigicola of New Guinea, and four insular taxa distributed both west and east of New Guinea (M. bannisteri, M. cooperae, M. howi, M. paveli). Six species (M. aerosus, M. caurinus, $M$. fulgens, $M$. obiensis, $M$. fraterculus, $M$. talaudium) from the Moluccan region should not be included in this group due to lack of data as well as their relative morphological divergence.

\section{Description}

Melomys burtoni from Halmahera (Figures 6, 7, and 11) is relatively small in body size (head-body length 110-141 mm) with short, dense, and soft pelage. Dorsal fur ranges from dark-brown to red-brown; the hairs are bicolored, uniformly gray to blackish at the bases (the proximal $1 / 4$ of the length) and brightly rufous distally. Dorsal guard hairs are soft, short, and pliable, project up to $7 \mathrm{~mm}$ beyond the overfur, and are glistening black for most of their length with some reddish tips. The ventral coat is pure white the length of the midventral region and grayish towards the flanks. We detect major chromatic differences between the pelage of an old adult $(n=1)$, and other adults $(\mathrm{n}=15)$. The old individual MZB 53533 has an overall darker coat and large body size, but is molecularly identical to all other $M$. burtoni specimens from Halmahera. The studied juvenile $(\mathrm{n}=1)$ display a finer and duller colour tone and a more greyish fur compared to the adults.

The snout of Melomys burtoni from Halmahera is reddish-brown to yellowish above, and white on the sides and underside. The rhinarium and lips are unpigmented. The eyes are small (diameter about $5 \mathrm{~mm}$ ). Vibrissae are dark gray. Mystacial and superciliary vibrissae are moderately long, extending slightly beyond the ears. The pinnae are relatively small and brown, with a sparse covering of reddish brown hairs on both the inner and outer surfaces.

The tail is nearly equal in length to the combined head and body length (only exceeding HBL in the specimen MZB 33533) (Tables 4 and 6). The tail is dark brown to blackish on the entire surface, except for the proximal portion $(10-25 \mathrm{~mm})$, which is unpigmented in some specimens (MZB 33533, 33552). Tail scales are smooth and less raised compared to those in species of the $M$. rufescens Division (Menzies 1996), and moderately large (14-15 rows $/ \mathrm{cm}$ ). There are three hairs per tail scale (each 1-2 mm long), which is characteristic of the $M$. cervinipes Division, as described by Menzies (1996). Tail hairs are dark brown. 


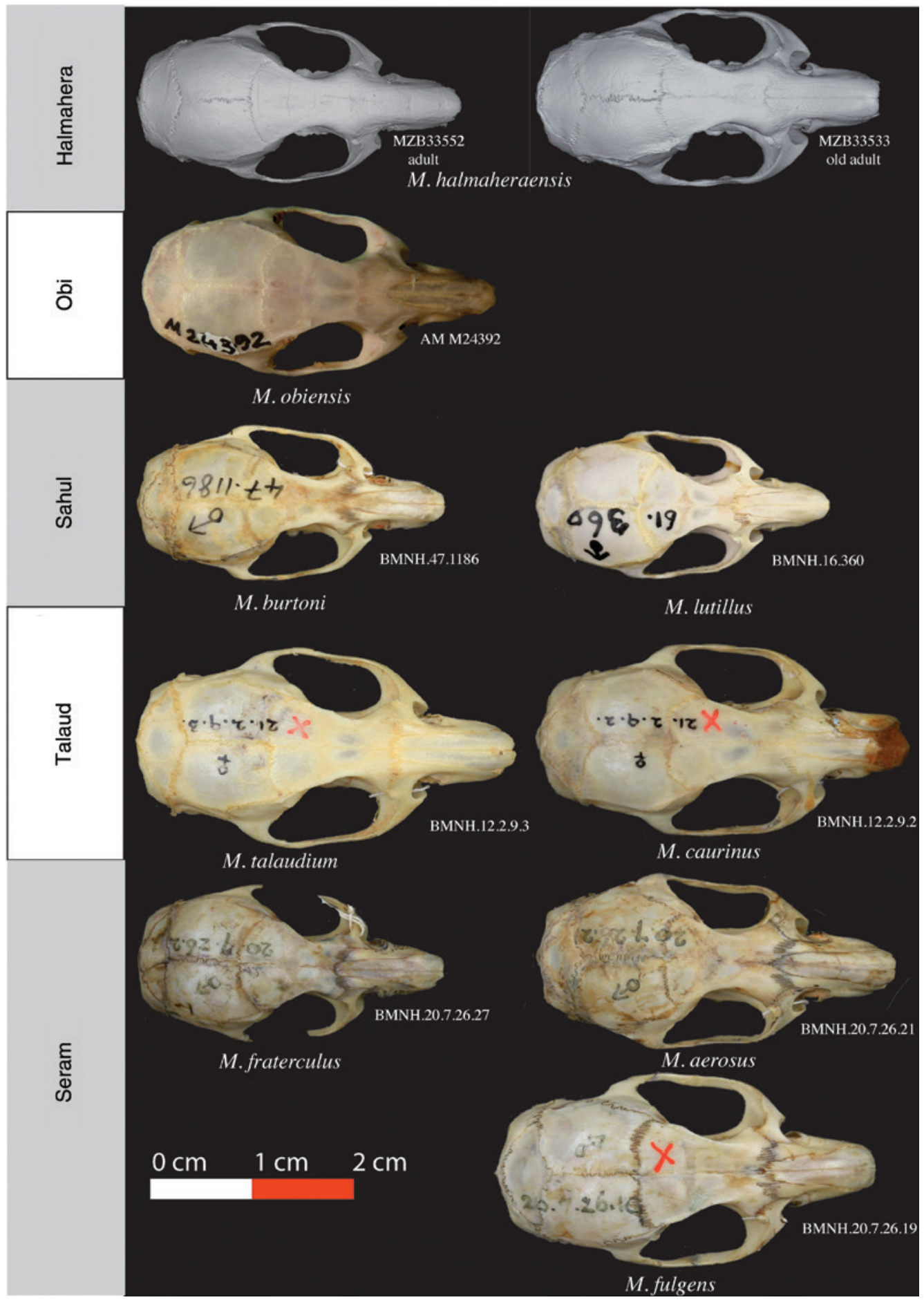

Figure 8: Dorsal view of crania of various Melomys species.

Top to bottom: M. burtoni (Halmahera, MZB 33552 young adult and MZB 33533 old adult), M. obiensis (Obi, AM M24392), M. burtoni (Australia, BMNH 61.360), M. lutillus (Papua New Guinea, BMNH 47.1186), M. talaudium (Talaud, BMNH 12.2.9.3), M. caurinus (Talaud, BMNH 12.2.9.3), . fraterculus (Seram, BMNH 20.7.26.27), $M$ aerosus (Seram, BMNH 20.7.26.21), M. fulgens (Seram, BMNH 20.7.26.19), $M$. paveli (Seram MZB 35961). Scale bar $01 \mathrm{~cm}$.

Dorsal surfaces of the forefeet and hindfeet are pale brown or unpigmented (Figures 6) and sparsely covered with short reddish or brownish hairs on top of the metapodials and laterally on the digits. At the base of each claw, long white hairs form ungual tufts. The pollex is very short and bears a flat nail. The other front digits are longer 


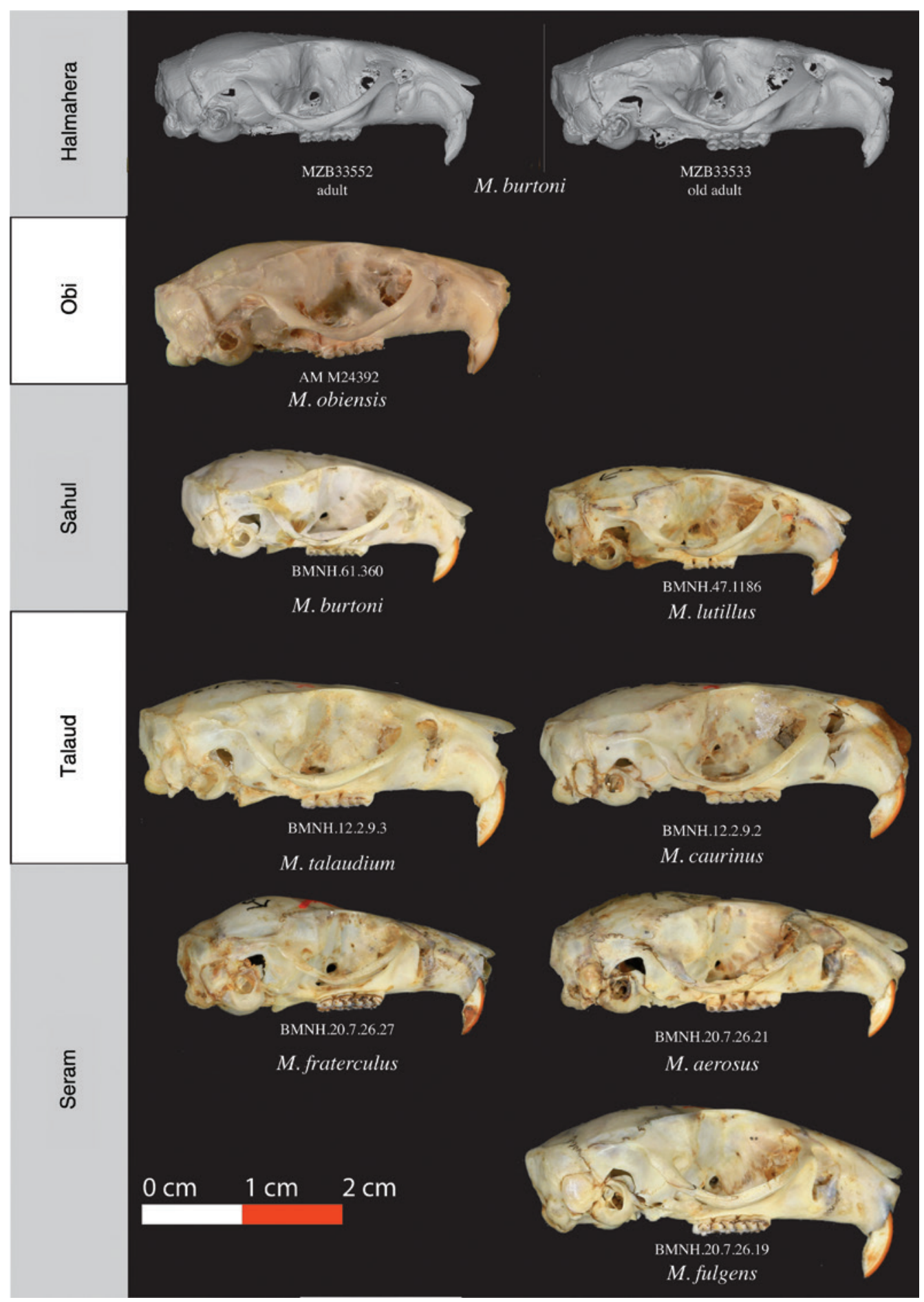

Figure 9: Lateral view of crania for various Melomys species.

Top to bottom: M. burtoni (Halmahera, MZB 33552 young adult and MZB 33533 old adult), M. obiensis (Obi, AM M24392), M. burtoni (Australia, BMNH 61.360), M. lutillus (Papua New Guinea, BMNH 47.1186), M. talaudium (Talaud, BMNH 12.2.9.3), M. caurinus (Talaud, BMNH 12.2.9.3), $M$. fraterculus (Seram, BMNH 20.7.26.27), $M$ aerosus (Seram, BMNH 20.7.26.21), $M$. fulgens (Seram, BMNH 20.7.26.19), $M$. paveli (Seram MZB 35961). Scale bar $01 \mathrm{~cm}$.

and broader with curved, sharp, white claws. Each palmar surface is hairless, unpigmented, and displays three interdigital pads and two large metacarpal pads. The hindfeet of Melomys burtoni from Halmahera are shorter than those of M. obiensis and those of M. frigicola (Tables 4 and 5). Digits are elongated and broad, and each bears a 


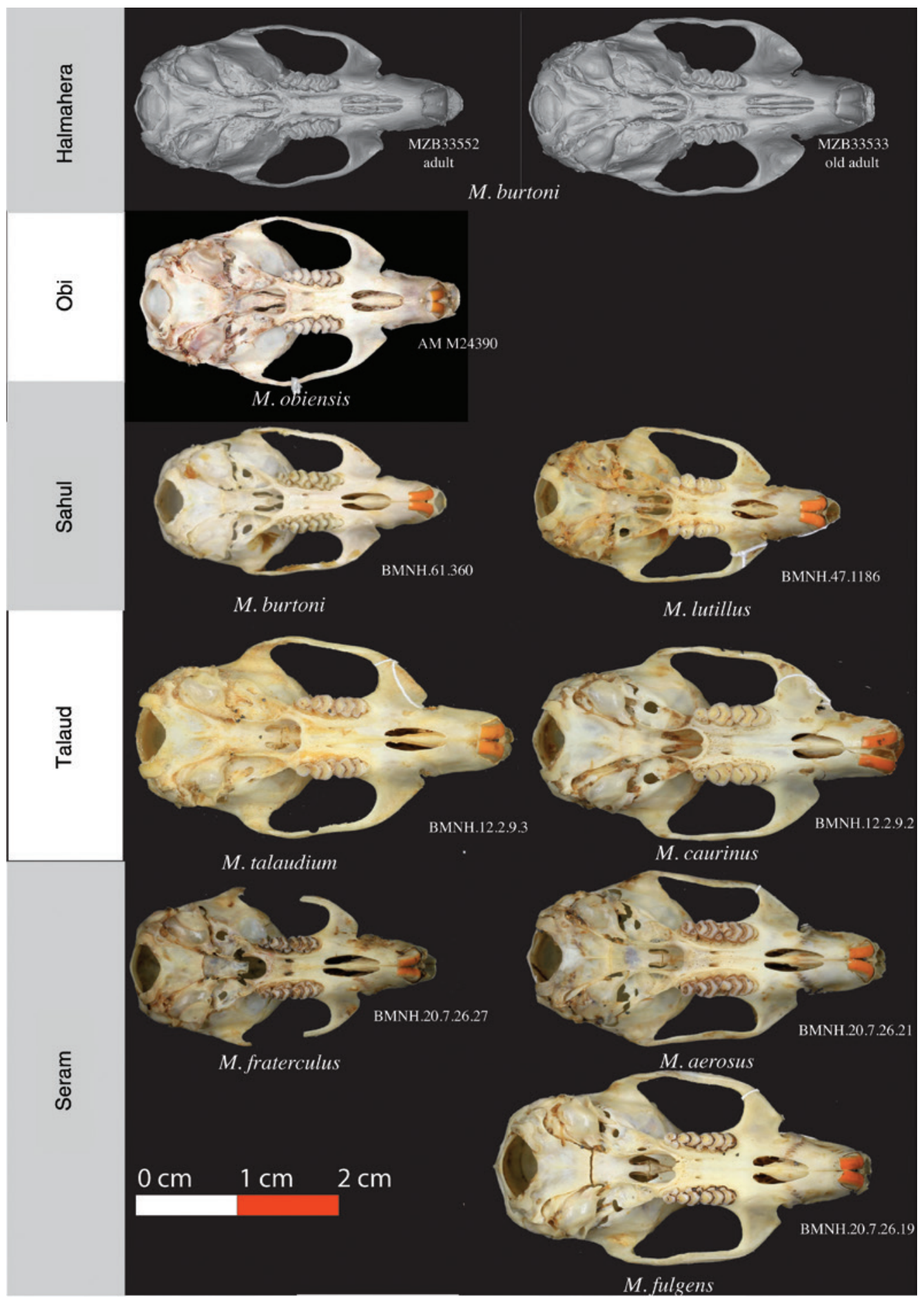

Figure 10: Ventral view of crania for various Melomys species.

Top to bottom: M. burtoni (Halmahera, MZB 33552 young adult and MZB 33533 old adult), M. obiensis (Obi, AM M24392), M. burtoni (Australia, BMNH 61.360), M. lutillus (Papua New Guinea, BMNH 47.1186), M. talaudium (Talaud, BMNH 12.2.9.3), M. caurinus (Talaud, BMNH 12.2.9.3), . fraterculus (Seram, BMNH 20.7.26.27), $M$ aerosus (Seram, BMNH 20.7.26.21), M. fulgens (Seram, BMNH 20.7.26.19), $M$. paveli (Seram MZB 35961). Scale bar $01 \mathrm{~cm}$.

pale claw that is short, sharp, and recurved. The hallux extends past the middle part of the medial digits. The 5th digit is slightly shorter than the medial digits and has a large associated interdigital pad. The plantar surface is naked and unpigmented, with four large interdigital pads, an elongate thenar pad, and a very small hypothenar pad. 


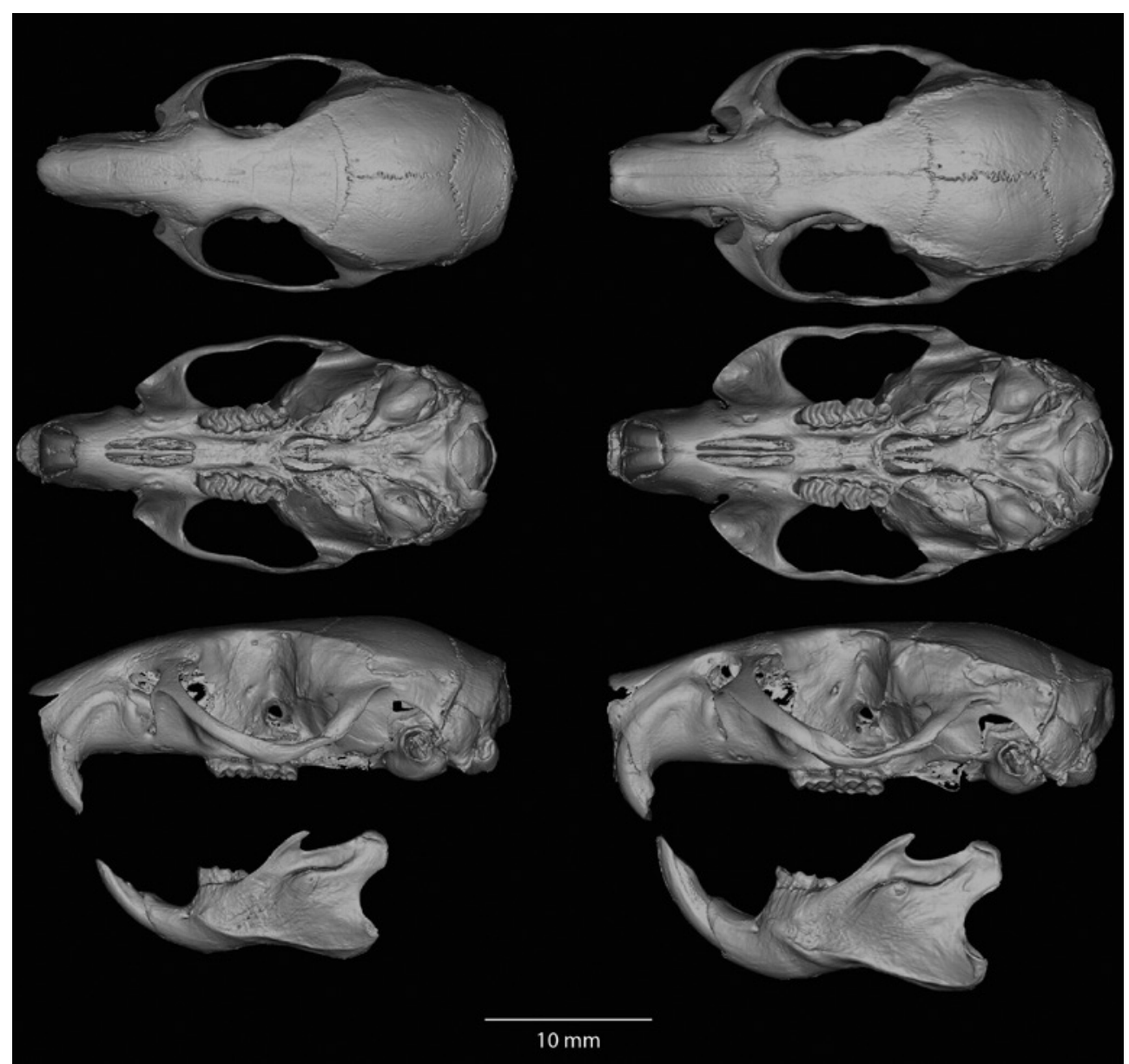

Figure 11: (Left) Skulls of $M$. burtoni (Halmahera, MZB 33552).

(Right) M. burtoni (Halmahera, MZB 33533), shown in dorsal (top), ventral (2nd row), and left lateral (3rd row) views of crania, lateral views of left mandible (4th row), and medial views of right dentary (bottom).

As in all Melomys species, it has only two pairs of inguinal teats $(0+2=4)$.

The skull of Melomys burtoni from Halmahera (Figure 11) is smaller than most Moluccan species of Melomys and similar to $M$. burtoni and allies in most dimensions (Figures 4, 8-10). In dorsal view, the rostrum is narrow and short (Figure 11). The interorbital region is moderately narrow and defined by concave borders. The postorbital region is elongate and the inflated braincase has a rounded outline. The temporal ridges that extend from the supraorbital region to the dorsolateral surfaces of the braincase are slightly developed. Robust zygomatic arches bow out from rostrum and braincase.

In lateral view (Figures 9 and 11), the dorsal profile of the skull is broadly convex from the slightly depressed nasal tips to the top of the frontals, straight over the frontals and parietals to the apex of the domed braincase, and sloping abruptly downward over the length of the interparietal. Nasal bones are short with sloping sides that give an angular shape to the tip of the rostrum. The posterior portion of the nasals are flat with nearly no concavity at the junction with the proximal end of the frontal. The zygomatic plate is narrower and the zygomatic notch shallower than in other Moluccan Melomys. The dorsal root and anterior portion of the zygomatic arch are slightly broadened. The squamosal root of the arch is positioned at the medial portion of the braincase. A subsquamosal fenestra is not present. Each auditory bulla is small (Figures 4, 5, 10 , and 11) and separated from the squamosal by a small postglenoid vacuity and from the alisphenoid by a narrow middle lacerate foramen. The lambdoid crest is poorly developed.

The ventral view of the skull (Figures 10 and 11) shows long incisive foramina (Figures 4 and 5) that project posteriorly beyond the anterior margins of the first molars. The palate is narrow (BPPM1 and BPPM3) and short (LBP). Each palatine foramen is large, positioned between the anterior and posterior roots of the M2, and opens anteriorly into a well-defined palatal sulcus that runs forward to the posterolateral margin of the incisive foramina. The 
mesopterygoid fossa is moderately broad. The lateral pterygoid fossae are shallow and contain large sphenopterygoid vacuities. The skull exhibits bony landmarks consistent with the primitive pattern of cephalic arterial circulation found in most murine rodents (Musser and Heaney 1992), as in other Melomys (Menzies 1996).

The upper and lower molars of Melomys burtoni from Halmahera are brachydont and broader compared to M. lutillus from Papua and M. burtoni from Australia (Figures 12 and 13; Tables 6 and 7). Each molar overlaps with its neighbour. The first upper and lower molars form nearly half of the entire toothrow, the second about onethird of the row, with the last molar much smaller than the others (Figures 12 and 13). The transverse laminae of the upper molars (rows 1 and 2 of M1 and row 2 of M2) display a posteriorly oriented, angular U-shape with a typically acuspidate chevron pattern (characteristic of Melomys, Paramelomys and Uromys). The first row is formed by a medium-sized cusp t1 slightly separated from a wide central cusp t2, which in turn is broadly fused with a smaller cusp t3. The second row is composed of a large backward-directed lingual cusp t4 that is attached to a wide and narrow central cusp t5 and a large labial cusp t6, which is smaller than t4. The third row is formed by a large, angular cusp t8 joined to a cusp t 9 that projects straight to the labial side. The second molar consists of two laminae with a medium-sized cusp t1. The first lower molar has an oblong outline and three rows of cusps (Figure 13). The anterior $2 / 3$ of the molar is formed by small anterolingual and anterolabial cusps that are slightly separated in unworn teeth from the second cusp row (metaconid, protoconid). The metaconid and protoconid are large, with a triangular shape, and fused in specimens displaying worn teeth (e.g. MZB 33533; Figure 13). A large entoconid and hypoconid comprise the third cusp row, behind which is a broad but anteroposteriorly narrow posterior cingulum. The subsquare second lower molar has two cusp rows and a posterior cingulum. The pattern and shape of the lamina are similar in cusp shape and pattern to first lower molar. There is

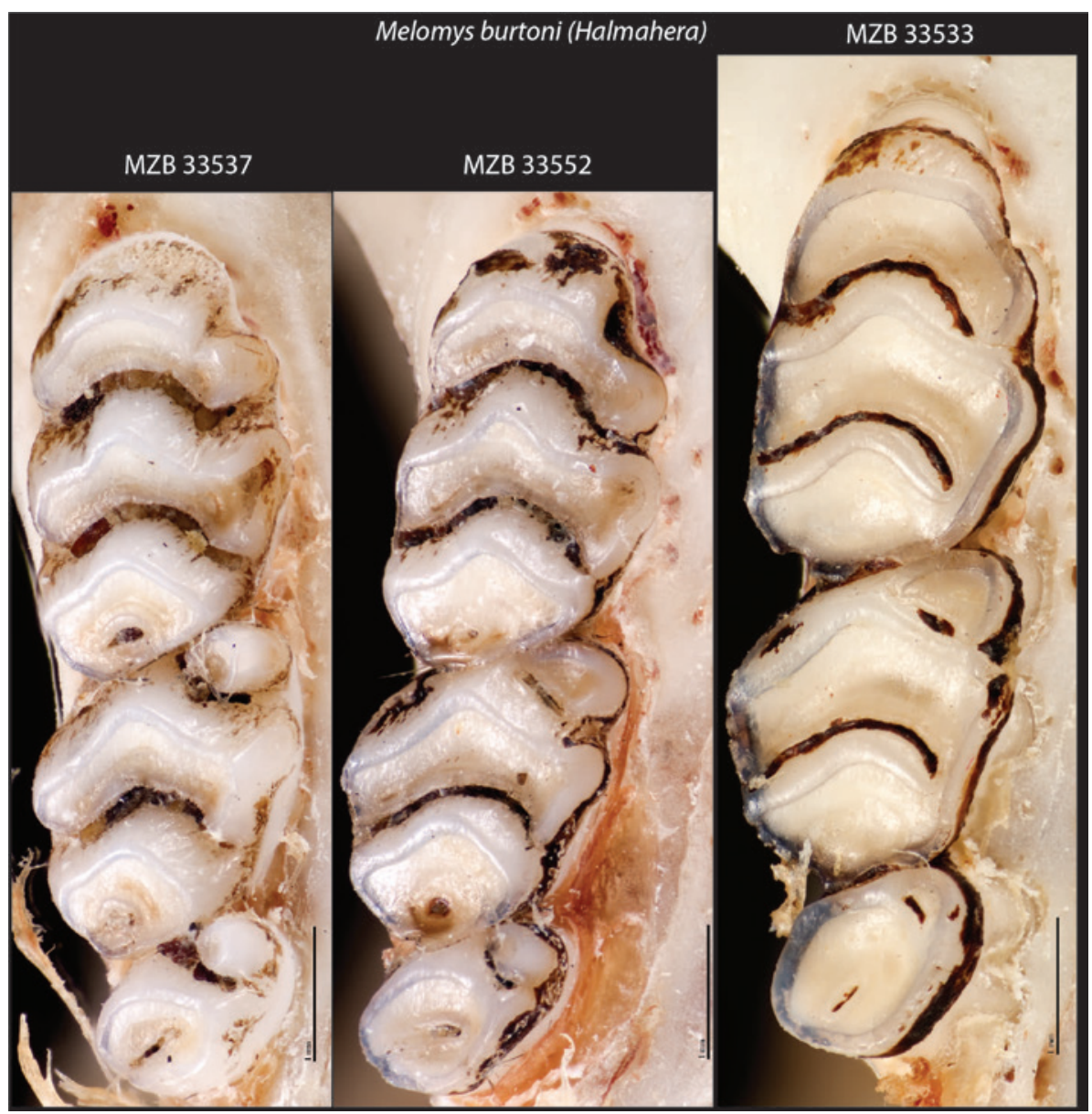

Figure 12: Occlusal views of right maxillary upper molar rows.

Left: Specimen of M. burtoni (Halmahera, MZB 33533), Middle and Right: M. burtoni (Halmahera, MZB 33552; MZB 33537). 


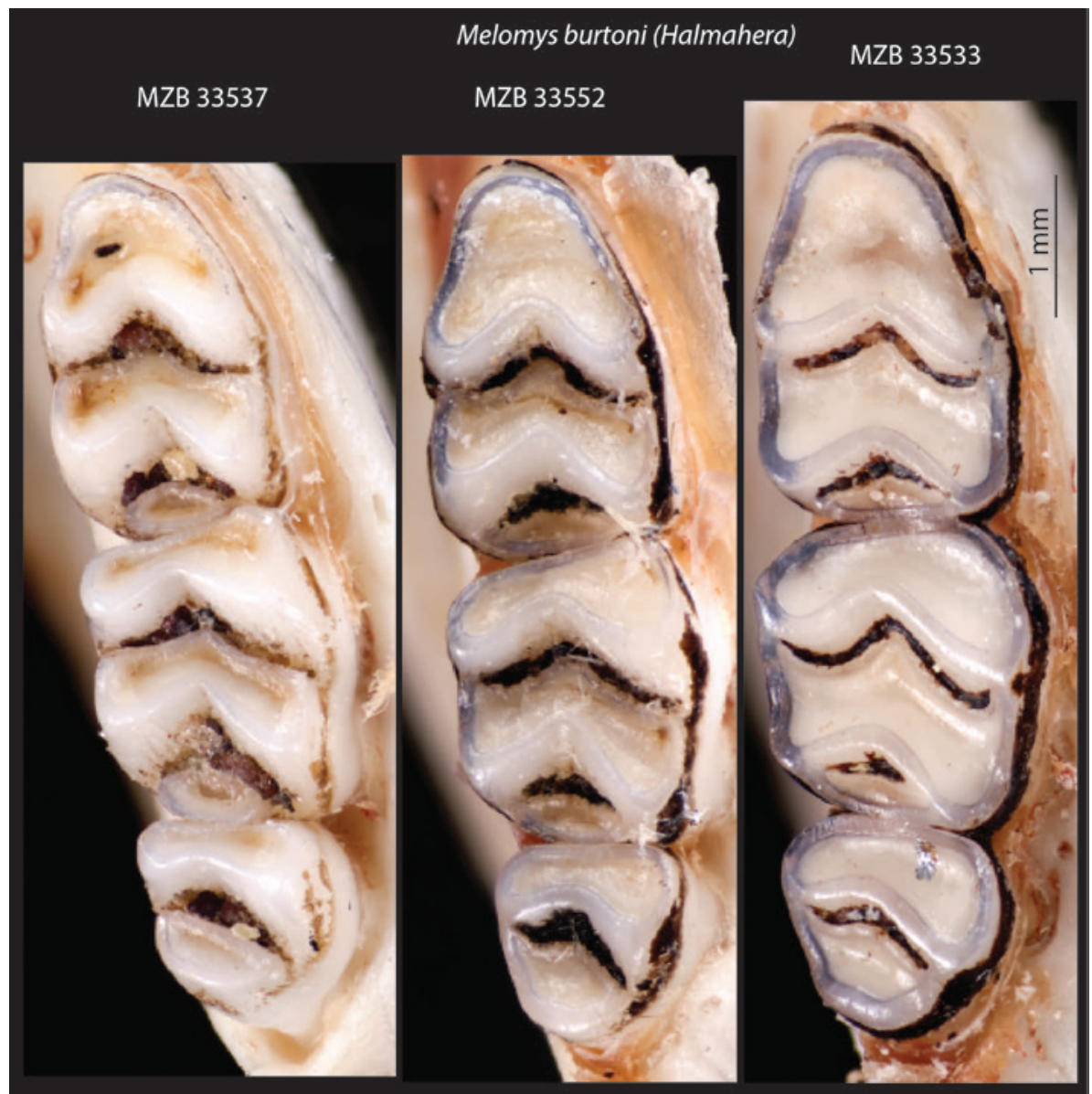

Figure 13: Occlusal views of right lower molar rows.

Left: Specimen of M. burtoni (Halmahera, MZB 33537), Middle and Right: Specimens of $M$. burtoni (Halmahera, MZB 33552; MZB 33533).

a small anterolabial cusplet on the anterolabial margin of the second lower molar close to the protoconid. The small third lower molar displays a rounded shape and a simple occlusal surface with two laminar cusp rows and a posterior cingulum. The molars of Melomys burtoni from Halmahera have multiple roots, which were identified by a $\mu \mathrm{CT}$ scanner. Below each first upper molar, we found one large anterior root, two smaller lingual anchors, one labial root and one large posterior root. Four roots anchor each second molar, there are two anterior roots and two posterior anchor. Three roots anchor each third molar, there are two anterior roots and one posterior anchor. One anterior and posterior roots coupled with smaller labial and lingual anchors attach to each first lower molar. The second lower molars are anchored by two anterior and two posterior roots. The third lower molars are anchored by two anterior and one posterior roots. The alveoli patterns of upper and lower molar roots seen in Melomys burtoni from Halmahera are similar to the patterns found for M. lutillus from Papua and M. burtoni from Australia.
Each dentary of Melomys burtoni from Halmahera is moderately long and stocky (Figure 11), with a short but stout coronoid process, robust condylar process and strong angular process. There is a concave curvature of the posterior margin of the dentary. The capsular process forms a prominent ridge parallel to the coronoid and anterior part of the condylar process. A prominent masseteric crest extends between the ventral margin and the labial part of the dentary just before the mental foramen. The mandibular foramen is located above a narrow ridge that runs caudally from the molar platform to the base of the condylar process.

\section{Natural history}

To date, Melomys burtoni from Halmahera has been recorded at three low elevation sites $(0-250 \mathrm{~m})$ in the southern part of Halmahera. The localities are situated within secondary habitats along the Ake-Sake River, 
Table 7: Cranial and dental measurements (in mm) of Melomys burtoni (Australia) and M. lutillus (New Guinea).

\begin{tabular}{|c|c|c|c|c|c|c|c|c|}
\hline & \multicolumn{4}{|c|}{ M. burtoni (Australia) ${ }^{\mathrm{a}}$} & \multicolumn{4}{|c|}{ M. lutillus (Papua) } \\
\hline & \multicolumn{3}{|c|}{ Male $(n=5)$} & \multirow{2}{*}{$\frac{\text { Female }(n=6)}{\text { Range }}$} & \multicolumn{3}{|c|}{ Male $(n=12)$} & \multirow{2}{*}{$\frac{\text { Female }(\mathrm{n}=17)}{\text { Range }}$} \\
\hline & Mean \pm SD & Range & Mean \pm SD & & Mean \pm SD & Range & Mean \pm SD & \\
\hline GLS & $30.17 \pm 2.75$ & $(27.85 / 32.94)$ & $30.38 \pm 4.8$ & $(27.02 / 33.95)$ & $28.44 \pm 1.08$ & $(27.19 / 30.03)$ & $28.26 \pm 0.35$ & $(27.40 / 28.79)$ \\
\hline IB & $4.65 \pm 0.09$ & $(4.22 / 5.20)$ & $4.65 \pm 0.12$ & $(4.13 / 5.30)$ & $4.43 \pm 0.03$ & $(4.22 / 4.63)$ & $4.43 \pm 0.07$ & $(4.15 / 4.77)$ \\
\hline ZB & $14.83 \pm 1.48$ & $(12.78 / 17.17)$ & $14.49 \pm 7.77$ & $(4.65 / 17.25)$ & $14.34 \pm 0.53$ & $(13.60 / 15.19)$ & $14.32 \pm 0.18$ & $(13.77 / 15.05)$ \\
\hline LR & $8.73 \pm 0.45$ & $(7.89 / 10.10)$ & $8.84 \pm 0.72$ & $(7.47 / 10.49)$ & $8.10 \pm 0.35$ & $(7.70 / 9.11)$ & $8.12 \pm 0.08$ & $(7.87 / 8.61)$ \\
\hline BR & $5.46 \pm 0.31$ & $(6.91 / 6.91)$ & $5.52 \pm 0.34$ & $(6.46 / 6.46)$ & $5.19 \pm 0.13$ & $(5.59 / 5.59)$ & $5.27 \pm 0.05$ & $(5.60 / 5.60)$ \\
\hline BBC & $12.81 \pm 0.52$ & $(11.41 / 14.01)$ & $12.56 \pm 0.64$ & $(10.75 / 13.90)$ & $12.60 \pm 0.24$ & $(11.92 / 13.13)$ & $12.6 \pm 0.11$ & $(12.23 / 13.16)$ \\
\hline $\mathrm{HBC}$ & $9.70 \pm 0.22$ & $(9.12 / 10.66)$ & $9.66 \pm 0.24$ & $(8.93 / 10.64)$ & $9.22 \pm 0.03$ & $(8.98 / 9.41)$ & $9.02 \pm 0.11$ & $(8.71 / 9.58)$ \\
\hline BZP & $3.89 \pm 0.20$ & $(3.05 / 4.60)$ & $3.91 \pm 0.28$ & $(2.99 / 4.59)$ & $3.69 \pm 0.07$ & $(3.35 / 3.97)$ & $3.40 \pm 0.04$ & $(3.16 / 3.72)$ \\
\hline LD & $7.99 \pm 0.63$ & $(6.67 / 9.49)$ & $8.06 \pm 0.92$ & $(6.75 / 9.63)$ & $7.71 \pm 0.25$ & $(7.27 / 8.36)$ & $7.62 \pm 0.05$ & $(7.35 / 7.89)$ \\
\hline PPL & $10.64 \pm 0.56$ & $(9.55 / 11.96)$ & $10.59 \pm 0.66$ & $(9.54 / 11.98)$ & $10.22 \pm 0.47$ & $(9.71 / 11.03)$ & $9.73 \pm 0.11$ & $(9.22 / 10.10)$ \\
\hline LBP & $5.93 \pm 0.12$ & $(5.38 / 6.51)$ & $5.85 \pm 0.17$ & $(5.09 / 6.52)$ & $5.56 \pm 0.13$ & $(5.19 / 5.95)$ & $5.53 \pm 0.09$ & $(5.21 / 5.94)$ \\
\hline BBPM1 & $2.66 \pm 0.08$ & $(2.23 / 3.15)$ & $2.68 \pm 0.1$ & $(2.20 / 3.22)$ & $2.51 \pm 0.01$ & $(2.39 / 2.58)$ & $2.58 \pm 0.04$ & $(2.26 / 2.89)$ \\
\hline ВВРМ3 & $3.86 \pm 0.11$ & $(3.35 / 4.32)$ & $3.88 \pm 0.18$ & $(3.33 / 4.60)$ & $3.69 \pm 0.1$ & $(3.33 / 4.12)$ & $3.71 \pm 0.05$ & (3.44/4.12) \\
\hline LIF & $5.05 \pm 0.31$ & $(4.28 / 6.32)$ & $5.05 \pm 0.44$ & $(4.18 / 6.78)$ & $4.75 \pm 0.15$ & $(4.35 / 5.16)$ & $4.73 \pm 0.08$ & $(4.38 / 5.06)$ \\
\hline BIF & $1.86 \pm 0.03$ & $(1.61 / 2.08)$ & $1.91 \pm 0.02$ & $(1.72 / 2.14)$ & $1.71 \pm 0.03$ & $(1.60 / 2.00)$ & $1.68 \pm 0.05$ & $(1.45 / 2.02)$ \\
\hline LB & $4.54 \pm 0.06$ & $(4.24 / 4.98)$ & $4.51 \pm 0.1$ & $(4.01 / 5.05)$ & $4.39 \pm 0.02$ & $(4.22 / 4.56)$ & $4.31 \pm 0.04$ & $(4.00 / 4.60)$ \\
\hline CLM13 & $5.67 \pm 0.17$ & $(5.09 / 6.29)$ & $5.48 \pm 0.19$ & $(4.65 / 6.13)$ & $5.10 \pm 0.02$ & $(4.95 / 5.26)$ & $5.24 \pm 0.04$ & $(5.02 / 5.57)$ \\
\hline $\operatorname{clm} 13$ & $5.69 \pm 0.23$ & $(4.82 / 6.28)$ & $5.49 \pm 0.27$ & $(4.80 / 6.28)$ & $5.16 \pm 0.02$ & $(5.04 / 5.38)$ & $5.18 \pm 0.06$ & $(4.84 / 5.56)$ \\
\hline BM1 & $1.64 \pm 0.01$ & $(1.45 / 1.88)$ & $1.60 \pm 0.02$ & $(1.43 / 1.81)$ & $1.53 \pm 0.00$ & $(1.48 / 1.56)$ & $1.57 \pm 0.00$ & $(1.52 / 1.68)$ \\
\hline bm1 & $1.53 \pm 0.02$ & $(1.33 / 1.74)$ & $1.49 \pm 0.01$ & $(1.28 / 1.73)$ & $1.39 \pm 0.00$ & $(1.31 / 1.45)$ & $1.39 \pm 0.00$ & $(1.34 / 1.45)$ \\
\hline $\mathrm{bm} 2$ & $1.66 \pm 0.02$ & $(1.41 / 1.81)$ & $1.65 \pm 0.01$ & $(1.47 / 1.82)$ & $1.52 \pm 0.00$ & $(1.43 / 1.58)$ & $1.52 \pm 0.01$ & $(1.41 / 1.71)$ \\
\hline bm3 & $1.32 \pm 0.02$ & $(1.05 / 1.55)$ & $1.29 \pm 0.01$ & $(1.06 / 1.48)$ & $1.17 \pm 0.01$ & $(1.10 / 1.30)$ & $1.24 \pm 0.02$ & $(1.13 / 1.44)$ \\
\hline
\end{tabular}

aAMH 154128-29; 154131-33; USNM 284423-28.

bAMNH 105754-56; 105757-60; 105762-69; 105770-71; 105866; 105964; 105967-69; 151204; 151207-11; USNM 585505.

approximately $1 \mathrm{~km}$ from the seashore of Tanjung Ulie (Cape Ulie). On one side of the river is a secondary forest, while the other side consists of gently sloping rocky terrain covered with shrubs, ferns, and grasses, adjacent to a heavily logged but formerly forest-covered area. These logged areas now consist of abandoned farmlands planted with coconuts, palms, fruit trees and cassava alongside pioneering forest trees and scattered elements of original forest vegetation. The ground surface on both sides of the river supports thick accumulations of humus. In the secondary forest, humus is about $25 \mathrm{~cm}$ thick, while in the farmlands it is about $5-10 \mathrm{~cm}$, and waterlogged. The river is shallow and the channel attains a maximum width of about $25 \mathrm{~m}$. Collecting at these localities took place in the dry season, when the flowing channel was only 2-5 m across, with a slow current. There are many fallen trees and old logs stretching across the river, and this allows small mammals like Melomys to move easily from one side to the other. The surrounding lowland rainforest in the area is tall (canopy $>20 \mathrm{~m}$ ) and characterized by the gymnosperm family Podocarpaceae and the angiosperm families Dipterocarpaceae (eight species dominated by Hopea and Shorea), Fagaceae (dominated by Lithocarpus), Guttiferacea (nine species dominated by Calophyllum), Lauraceae (seven species dominated by Litsea and Eugenia) and Myrtaceae (11 species dominated by Eugenia and Pometia), as well as tree ferns, Ficus, rattans, bamboos, non-woody climbers, orchids, epiphytes and bryophytes (Sidiyasa and Tantra 1984; Whitmore et al. 1984; Edward et al. 1990; Flannery 1995a,b; Monk et al. 1997). Specimens of Melomys burtoni were captured in folding rat traps placed in runways under logs lying on the ground, at burrow openings, on top of dead tree trunks, in scrub or in subsurface spaces between tree roots. The length of Melomys burtoni tail as well as the fact that the species was caught only on the ground (some traps were placed on logs and vines but not high in the canopy) in disturbed habitat might indicate a mostly terrestrial or scansorial adaptation compared to another more arboreal species ( $M$. fraterculus or $M$. frigicola). All the specimens were trapped with roasted coconut and peanut butter bait in second growth areas (disturbed forest, scrubland, young regrowth) along the Ake Jira and Ake Sake rivers. Melomys burtoni is apparently omnivorous, with examined stomach contents $(\mathrm{n}=3)$ containing the remains of small fruits, vegetable 
Table 8: Cranial and dental measurements (in $\mathrm{mm}$ ) of the holotypes of Melomys talaudium (Talaud Islands), M. caurinus (Talaud Islands), and Melomys obiensis (Obi Island).

\begin{tabular}{|c|c|c|c|}
\hline & M. talaudium ${ }^{\mathrm{a}}$ & M. caurinus $^{\mathrm{b}}$ & M. obiensis ${ }^{c}$ \\
\hline & Female $(n=1)$ & Female $(n=1)$ & Female $(n=1)$ \\
\hline GLS & 39.1 & 38.2 & NA \\
\hline IB & 5.83 & 6.30 & 5.53 \\
\hline ZB & 20.72 & 19.81 & NA \\
\hline LR & 11.22 & 10.50 & 9.59 \\
\hline $\mathrm{BR}$ & 7.39 & 6.95 & 5.46 \\
\hline $\mathrm{BBC}$ & 14.62 & 14.15 & NA \\
\hline $\mathrm{HBC}$ & 10.95 & 10.73 & NA \\
\hline BZP & 5.87 & 5.17 & 4.10 \\
\hline LD & 11.81 & 10.63 & 9.69 \\
\hline PPL & 13.92 & 14.11 & NA \\
\hline LBP & 9.00 & 9.51 & NA \\
\hline BBPM1 & 3.97 & 3.65 & NA \\
\hline ВВРМ3 & 5.09 & 4.75 & NA \\
\hline LIF & 6.16 & 5.34 & 5.83 \\
\hline BIF & 2.30 & 2.50 & NA \\
\hline LB & 5.02 & 4.58 & 5.40 \\
\hline CLM13 & 7.49 & 7.95 & 6.19 \\
\hline $\operatorname{clm} 13$ & 7.43 & 7.41 & 6.14 \\
\hline BM1 & 2.15 & 2.43 & 1.79 \\
\hline $\mathrm{bm} 1$ & 2.07 & 2.38 & 1.68 \\
\hline $\mathrm{bm} 2$ & 2.29 & 2.52 & 1.91 \\
\hline bm3 & 1.88 & 2.06 & 1.54 \\
\hline
\end{tabular}

NA, broken.

${ }^{\mathrm{a} B M N H .21 .2 .9 .3 . ~}$

'BMNH.21.2.9.2.

'BMNH.3.4.10.1.

matter and a few arthropods. Specimens collected at the different localities between 30-31 January 2010 and 6-23 June 2010 included three young adult males with abdominal testes, four adult males with scrotal testes, and six adult females with inactive reproductive tracts. Other non-volant mammals trapped in the same areas as M. burtoni included Rattus morotaiensis, Rattus exulans, Rattus tanezumi (R3 haplotype: Pagès et al. 2013), Mus cf. musculus, Phalanger ornatus, Suncus murinus and Viverra tangalunga.

\section{Expanded morphological comparisons}

Our molecular phylogenetic comparisons recovered a monophyletic clade containing the Australo-Papuan taxa Melomys burtoni and M. lutillus, as well as the Moluccan taxa M. burtoni from Halmahera and M. paveli (clade burtoni in Figure 3). Within this cluster, Melomys burtoni from Halmahera was recovered in a paraphyletic assemblage with respect to $M$. burtoni from Australia and M. lutillus from Papua (Figure 3). Consequently, we concentrate most attention on comparisons of Melomys burtoni from Halmahera with populations of $M$. burtoni and $M$. lutillus (see also Figure 3 and results), along with a few other closely related Moluccan taxa (especially $M$. paveli). Melomys burtoni from Halmahera can be distinguished externally from these related taxa by pelage colour and external dimensions (Tables 4 and 5, Figures 6 and 7). We also provide summaries of qualitative and quantitative morphological distinctions between Melomys burtoni from Halmahera and various Moluccan and Australo-Papuan relatives (Tables 6-9).

\section{Melomys burtoni from Halmahera, Melomys obiensis, and $M$. paveli}

Halmaheran Melomys deserve especially close comparison with $M$. obiensis, endemic to the islands of Obi and Bisa, which is the only previously described species of Melomys in the North Moluccas (Flannery 1995a), and $M$. paveli of Seram, now shown to be a close phylogenetic relative of Melomys burtoni. Compared to M. obiensis, Melomys burtoni from Halmahera differs in its smaller mean head-body length (Tables 4 and 5), smaller feet, longer ear, and relatively shorter tail length (tail 103\% of HBL for Melomys burtoni from Halmahera compared to $128 \%$ in M. obiensis). Both Melomys burtoni from Halmahera and $M$. obiensis have pelage that is white ventrally and reddish dorsally, but the dorsal pelage of $M$. burtoni is darker in overall coloration (Figures 6 and 7).

Disparity in physical size between Melomys burtoni and $M$. obiensis is reinforced by contrasts in cranial and dental measurements (Tables 6 and 8) and our geometric morphometrics results (Figure 4). A larger skull and a longer and narrower rostrum are characteristic of Melomys obiensis (see Tables 6 and 8; Figures 4 and 8). Other major contrasts in the skull are the relatively small auditory bullae and the longer incisive foramina of $M$. burtoni as highlighted by the PCA presented in Figure 4 as well as in the Tables 4 and 8 . We have not identified any significant dental contrasts between $M$. burtoni and $M$. obiensis. The dorso-lateral margins of the interorbital and postorbital regions in $M$. burtoni are broadly concave, the outline resembling the base of a vase. In M. obiensis, the interorbital region quickly flows into a broad postorbital region bounded by long and straight but slanting margins. Moreover the postorbital region resembles a broad wedge, and is not vase-shaped. The conformation of $M$. obiensis is usually associated with arboreal/scansorial murines, a 


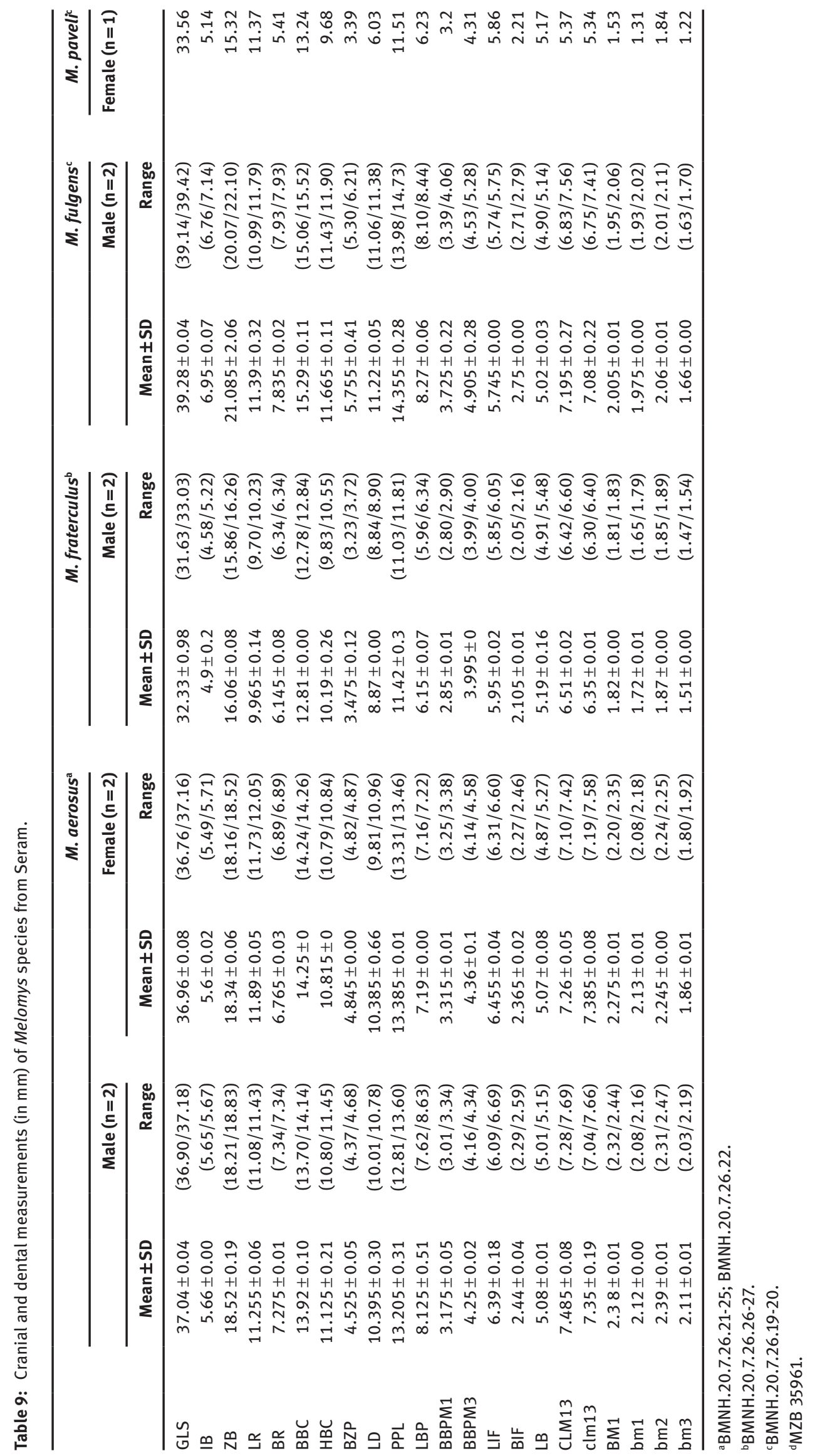


habitus reinforced by its very long tail relative to length of head and body. This observation is in striking contrast with the fact that $M$. burtoni display a nearly equal tail length relative to length of head and body and might be more terrestrial than $M$. obiensis.

Melomys paveli of Seram differs from M. burtoni by its bright red-brown dorsal and pure white ventral coloration. Cranially, $M$. paveli is a very divergent taxon (see molecular and morphological characters, Figure 4; Tables 5, 6, and 9) that is convergent on M. rufescens (cf. Helgen 2003 for the description of $M$. rufescens paveli). Our comparisons reveal that $M$. burtoni from Halmahera has a longer tympanic bulla than M. paveli (Figure 4, PC1). In the rostrum, the incisive foramina are respectively longer and broader in M. burtoni compared to M. paveli (Figures 4 and 5; Tables 6 and 9). Melomys paveli was originally named and described as a subspecies of $M$. rufescens by Helgen (2003), but Musser and Carleton (2005:1379) proposed that a better hypothesis was to consider $M$. paveli as a distinct species, which was also an option suggested by K. Helgen. Results from gene-sequence analysis (Figure 3) and geometric morphometrics (Figure 4) links M. paveli to the $M$. burtoni group and unambiguously disassociates it as an insular representative of $M$. rufescens.

Other Moluccan Melomys differ from Melomys burtoni from Halmahera in body size (Tables 4 and 5; Figures 6 and 7) and/or coloration, e.g. M. fulgens of Seram is larger and has a bright orange dorsum and white venter; M. aerosus of Seram is larger and has a brown dorsum and dusky venter); $M$. fraterculus of Seram has pale brown upperparts and a longer tail; and the two Talaud Island species ( $M$. caurinus and $M$. talaudium) are both larger in body size and have bright orange dorsal fur and pure white venters. Our palatal morphospace result (Figure 4) reflects some of the results of Musser and Carleton (2005) as we recover three possible morphological affiliations for the Moluccan species: (1) a M. cervinipes relationships for M. bannisteri, M. fraterculus, $M$. howi, and M. obiensis; (2) a $M$. leucogaster group including $M$. caurinus, and $M$. talaudium. The morphospace of $M$. cooperae seems to be different from the $M$. rufescens group as it is there grouped with other south Molucca taxa (M. aerosus, M. paveli).

\section{Melomys burtoni from Halmahera, Melomys burtoni from Australia, Melomys lutillus and M. frigicola from Papua}

In body size and relative tail length, Melomys lutillus (TL/ HBL 100\%), M. frigicola (TL/HBL 109\%) and M. burtoni (TL/HBL 106\%) recall species of $M$. burtoni from Halmahera (TL/HBL 103\%), but in many ways the resemblance is superficial. Compared to M. burtoni (Halmahera), $M$. burtoni (Australia), M. frigicola (New Guinea), and M. lutillus (New Guinea) display some differences in fur coloration. M. burtoni from Halmahera with its red-brown dorsal coat and white ventral fur is superficially different from the three remaining taxa which are, respectively (1) gray brown to reddish brown above and white, gray or cream on the belly for $M$. burtoni from Australia, (2) yellow-brown dorsal and gray-buff to pure white ventral colorations in M. frigicola from Papua and (3) reddish gray dorsally and mottled red or white ventrally in M. lutillus from Papua. $M$. burtoni (Halmahera) also differs from these species in having longer and larger ears (Tables 4 and 5).

Cranial conformation in Melomys burtoni (Halmahera) is remarkably similar to specimens of Australo-Papuan $M$. lutillus, M. frigicola, and M. burtoni. Occipitonasal length, interorbital breadth, length of rostrum, breadth of zygomatic plate, and breadth of upper molars are similar across these species, as judged by mean values for these dimensions (Tables 6-9). However, in nearly all other cranial dimensions, $M$. burtoni from Halmahera averages smaller than the other taxa. For example, it averages significantly smaller for the width of the zygomatic plate, length of the diastema, and length of maxillary tooth row (Tables 4-9), results confirmed by our morphometric analyses (see Figure 5 as well as the Result section). Proportional differences also differentiate the Halmaheran endemic population. For example, the incisive foramen is slightly longer compared to the length of the rostrum (LIF/LR 61\%, see also Figure 5) which is different from Australian Melomys burtoni (LIF/LR 57\%), Papuan M. frigicola (LIF/LR 57\%) and Papuan M. lutillus (LIF/LR 58\%); the zygomatic plate of Halmaheran $M$. burtoni is relatively narrower than in Australian M. burtoni, Papuan Melomys frigicola or Papuan M. lutillus species. First upper molar (BM1) and lower molars are narrower than in Australo-Papuan M. burtoni, M. lutillus and M. frigicola (Tables 6-9). It is mainly the length of the incisive foramina, smaller skull measurements and its smaller bulla that discriminate Halmaheran population from Australo-Papuan M. burtoni and $M$. lutillus (Figure 5, Tables 6-9).

Cranial and dental similarities and distinctions are summarized in Figure 5, where the distribution of specimen scores are projected on the first and second components extracted from a Principal Components analysis. Animal size captured more variation than species ID, with large skull species clustering to the left and small skull species to the right on the first PC axis. All Halmaheran Melomys burtoni clustered within the same large cloud of points that also included M. paveli (but see previous part) and some specimens of Australian M. burtoni. These 
large skull taxa are similar in absolute cranial dimensions, and differ from other small skull M. burtoni and $M$. lutillus (Figure 4; Tables 6-9). Although most observed variation was due to skull size, on the second component, M. burtoni (Halmahera) is slightly distinguishable from M. burtoni and M. lutillus and segregates from AustraloPapuan M. burtoni and M. lutillus based primarily on the incisive foramina length, consistent with our visual comparisons of these species' skulls (Figures 8-10).

\section{Discussion}

\section{Phylogenetic relationships}

Although Halmaheran Melomys is distinguished morphologically from each of its close relatives, which include Australian M. burtoni, Papuan M. lutillus and Seramese $M$. paveli, there is no clear support for its monophyly in our current molecular phylogenetic comparisons, and further analyses will be required to reveal the relationships within the burtoni clade (Figure 2) and test for its species or subspecies status. Past accounts of Australo-Papuan Melomys (Flannery 1995a,b) have informally referred to a "Melomys lutillus" group (Thomas 1913) but we decide herein to use the name $M$. burtoni group (Ramsay 1887), after the earliest named member of this assemblage. We think that several additional Moluccan species also are of uncertain status (e.g. M. paveli, M. howi, M. bannisteri) and will required a proper molecular and morphological revision. Indeed, the existing molecular data of Bryant et al. (2011) is the only available dataset for the group, and the markers are not variable enough to discriminate species in a group that evidently has undergone recent and explosive diversification in several biogeographic regions and habitats across the greater Australo-Papuan region (clade burtoni, age $=0.5-1.4$ Myr; Bryant et al. 2011). Further analyses using more appropriate, fast-evolving markers (eg. Cytb, RadSeq, Introns or microsatellites; Bryant 2013) or even several additional nuclear markers (Pagès et al. 2010, 2013, Rowe et al. 2011) will be necessary to study molecular systematics of this recently radiated species group. The lack of reciprocal monophyly between Moluccan and Australo-Papuan M. burtoni, M. paveli and $M$. lutillus suggests either a history of recent gene flow between these groups or a lack of lineage sorting in the context of recent (and ongoing) diversification within Australo-Papuan insular systems (e.g. possibly facilitated by sea level fluctuations). Our results, along with the work of Bryant et al. (2011), suggest a relatively recent (in geological terms) geographical range expansion of this group (clade burtoni) from Australia and New Guinea into the Moluccas, leading to incipient speciation in this widespread and diverse genus. This expansion seems to have led independently to morphological divergence of $M$. burtoni on Halmahera and maybe M. paveli on Seram (the last originally classified as a subspecies of $M$. rufescens; Helgen 2003), and perhaps other Moluccan Melomys that are as yet unsampled in molecular phylogenetic comparisons. Our results indicate the need for continuing morphological and molecular investigations into the diversity and relationships among species of Melomys, especially those endemic to the scatter of islands between Sulawesi and the Australo-Papuan region, a contention also expressed by Bryant et al. (2011) and Bryant (2013). In terms of systematic complexity within a recent and rapid radiation, Melomys presents taxonomic challenges similar to the situation in Australo-Papuan Rattus (Rowe et al. 2011).

\section{Biogeographical implications}

From the present study and that of Fabre et al. (2013), it is clear that the rodent fauna of Halmahera is of complex origin, with each of the three native taxa having a distinct biogeographic origin. The affinity of the recently described Halmaheramys bokimekot is with the Tribe Rattini and, more specifically, with an endemic Sulawesian clade comprised of the genera Bunomys, Paruromys and Taeromys. Fabre et al. (2013) estimated that the ancestor of Halmaheramys crossed from Sulawesi during the Pliocene. In contrast, the second native member of tribe Rattini, Rattus morotaiensis (also found on Morotai and Bacan islands), appears to be a member or a close relative of the Australo-Papuan Rattus group (Fabre et al. 2013). According to Rowe et al. (2011), this group is the product of an explosive radiation during the mid- to late Pleistocene, hence the ancestor of $R$. morotaiensis is unlikely to have entered the Halmahera Group much before 1 mya. Finally, the hydromyine rodent Melomys burtoni from Halmahera is very closely related to $M$. burtoni, $M$. lutillus and $M$. paveli of Australia, New Guinea and Seram, respectively, and dispersal of this group through the region is likely to be significantly younger again. Our discovery reinforces the fact that Halmahera constitutes a unique transition zone in the Moluccas for the murines, colonized from both the East and the West.

Halmahera has a long geological and biogeographical history closely tied to that of Australo-Papuan area (Hall et al. 1988; Hall 2009, 2013). Several biogeographical studies have demonstrated a close link between these 
faunas (e.g. de Jong 1998, Helgen 2003). Based inferred paleomaps (Hall 2013) models, the rude units that currently comprise Halmahera island began to move from east to west along the Pacific plate during the Miocene before to reach its current location (Hall 1988, 2002, 2009, 2013, Hall and Nichols 1990) and is currently closer to Sulawesi and Philippines than during most of its geological history. Hence, we suggest that its proximity from Australo-Papuan region (also called Sahul) during the Tertiary may have generated potential stepping-stone connections necessary for the arrival of Melomys from Eastern Indo-Pacific. The Halmahera and Sangihe volcanic arc activities (Hall and Nichols 1990, Hall 2009) might have offered opportunity to connect Papua, Halmahera and Talaud by chains of neighbouring islands, and may explain arrival of Melomys on most of the Northern Moluccan islands. This colonization pattern may also be linked with the beginning of climatically induced sealevel lowstands in the Late Pliocene (Haq et al. 1987, De Graciansky et al. 1998). As Halmaheran Melomys display little molecular divergence from its close relative from Australo-Papua, this second hypothesis is more likely to explain their arrival in Halmahera. We note that Melomys have never been reported as a commensal species, so a hypothesis of transport by humans can likely be excluded. Based on our results, the $M$. burtoni group seems to have radiated through the Indo-Pacific archipelago thanks to Plio-Pleistocene sea level and colonized via rafting to at least the two Moluccan islands of Halmahera and Seram. Seram has a Melomys fauna comprising four endemic Melomys species, which is unique in the Moluccas. These Melomys have probably invaded this island at various times from the Australo-Papuan region. Further discoveries are required to test whether multiple origins of the Melomys fauna applies to Seram as well as other large Northern Moluccan islands, such as Bacan, Obi and Buru.

\section{Distribution of murines from Northern Moluccas}

The discovery of Melomys burtoni on Halmahera fills in a puzzling gap in the distribution of Melomys, previously documented on landmasses directly to the south (M. obiensis, Obi and Bisa), north-east (M. talaudium and M. caurinus, Talaud Islands), and west (M. rufescens and many other species, Waigeo and New Guinea) of the large island of Halmahera and its neighbouring satellite islands. Our molecular studies reveal that Halmaheran $M$. burtoni is closely related to M. burtoni, M. lutillus and M. paveli, and there are morphological similarities to other small Melomys that remain unavailable for sequencing, most notably $M$. frigicola. This suite of taxa typically occurs in relatively open habitats, such as tropical grassland, woodland, or forest edges (Watts and Aslin 1981, Flannery 1995a, 1995b, Menzies 1996). M. burtoni was discovered in secondary forest and forest edge habitats, which are common throughout Halmahera and adjacent islands, such that it will be surprising if the species is not found to be more widespread in the North Moluccas with additional survey effort.

We suspect that many additional species of native murines, including species of Melomys, remain to be discovered in the Moluccas. The only island in the Moluccas for which the rodent fauna has been surveyed in any detail, across a range of habitats and elevations, is Seram (Thomas 1920, Helgen 2003), now known to support at least 10 species of rodents of which six are endemic species, including four species of Melomys (Helgen 2003). The neighbouring large island of Buru has never been the target of an extensive survey effort to document small mammals (Helgen 2003, Amori et al. 2008), but undoubtedly harbours undiscovered endemics. In 2011 one of us (P.-H. Fabre) observed a potential species of Melomys in secondary forest along a river at $1000 \mathrm{~m}$ in the Kapalat Mada area during a 3-week bird collecting expedition to Buru (with ZMUC and MZB personnel). Like Seram, the large and high islands of Buru, Halmahera, Obi and Bacan could each support multiple, as yet undiscovered species of Melomys.

\section{Conclusions}

For centuries the unique nature of the plants and animals found within the Wallacean region has captured the imagination of many naturalists. This pattern, a Wallacean hallmark, is shared with Sulawesi, famous for being a remarkable zone of biotic overlap for non-volant mammals, where western components of Asian origin (squirrels, ungulates, civets, etc.) and eastern components of Sahulian origin (endemic phalangers) co-occur. Our investigation on the rodent fauna of Halmahera has not only major implication for systematics (cf. Melomys burtoni and Halmaheramys bokimekot) but provides also important clues concerning Wallacean biogeography. Halmahera bears three endemic taxa that each colonized independently; further expeditions in the area will be necessary to shed light on the biodiversity of these Moluccas islands. Among rodents, the Sulawesi fauna comprises 
mainly rats and squirrels from a Southeast Asian origin (Musser et al. 2010, Fabre et al. 2013). In view of recent Moluccas studies (Helgen 2003, Fabre et al. 2013, present report) the Halmahera and Seram islands displays a clearer mixed Australo-Asian zoogeographic pattern ("Wallace hall") compared to Sulawesi, with species coming both from east of Lyddeker's line and west of Wallace line. In summary, dispersal from Australo-Papuan region funded role in the distribution and structure of Moluccan murine assemblages, but much remains to be learned about murine biodiversity in this complex and unexplored region.

Acknowledgments: We thank Guy G. Musser, DeeAnn Reeder and one anonymous reviewer for their discussion and corrections concerning this manuscript. We thank the State Ministry of Research and Technology (RISTEK, permit number: 028/SIP/FRP/SMII/2012) and the Ministry of Forestry, Republic of Indonesia for providing permits to carry out fieldwork in the Moluccas. Likewise we thank the Research Center for Biology, Indonesian Institute of Sciences (RCB-LIPI) and the Museum Zoologicum Bogoriense for providing staff and support to carry out fieldwork in the Moluccas. We thank Anne-Claire Fabre, Julien Benoit, Lionel Hautier, Jessica Oswald, Tim Flannery, and Boeadi for helpful discussion. For granting access to specimens under their care and other assistance, we are grateful to Darrin Lunde and Nicole Edmison (USNM), Eileen Westwig, Neil Duncan and Robert Voss (AMNH), Géraldine Véron, Violaine Nicolas, and Christiane Denys (MNHN), Hans Baagøe and Mogens Andersen (ZMUC), Sri Sulandari (LIPI), Paula Jenkins and Roberto Portela Miguez (BMNH), and Sandy Ingleby (AM). We thanks Renaud Lebrun (ISEM, Montpellier 2 University, France) and MRI platform for scanning the skulls of Melomys burtoni from Halmahera. P.-H.F. acknowledges the Danish National Research Foundation and a National Geographic Society Research and Exploration Grant (8853-10) for funding the Center for Macroecology, Evolution and Climate. P.-H.F. acknowledges the National Geographic Society for funding fieldwork in Indonesia. MP is currently funded by an FRSFNRS fellowship (Belgian Fund for Scientific Research). P.-H.F. acknowledges the SYNTHESYS Foundation for funding his work in the BMNH collections (GB-TAF-2735 and GB-TAF-5026). Analyses were performed on the CBGP HPC computational platform. This project was partly supported by the network "Bibliothèque du Vivant" funded by the CNRS, the Muséum National d'Histoire Naturelle, the INRA and the CEA (Centre National de Séquençage). P.-H.F. was funded by a Marie-Curie fellowship (PIOF-GA2012-330582-CANARIP-RAT). P.-H.F. wants to acknowledge
Carsten Rahbek (Center for Macroecology Evolution and Climate) who generously funds his recent field research in the Moluccas. This publication is contribution no. 2017035 of the Institut des Sciences de l'Evolution de Montpellier (UMR 5554-CNRS-IRD).

\section{References}

Alston, E.R. 1877. On the rodents and marsupials collected by the Rev. G. Brown in Duke of York Island, New Britain and New Ireland. Proceedings of the Zoological Society of London 1877: 123-127.

Amori, G., S. Gippoliti and K.M. Helgen. 2008. Diversity, distribution, and conservation of endemic island rodents. Quat. Int. 182: 6-15.

Aplin, K.P., Helgen, K.M. 2010. Quaternary murid rodents of Timor. Part I: New material of Coryphomys buehleri Schaub, 1937, and description of a second species of the genus. Bull. Am. Mus. Nat. Hist. 341: 1-80.

Bellwood, P., G. Nitihaminoto, G. Irwin, Gunadi, A. Waluyo and D. Tanudirjo. 1998. 35,000 years of prehistory in the Northern Moluccas. Modern Quaternary Research in Southeast Asia 15: 233-275.

Bookstein, F.L. 1991. Morphometric tools for landmark data: geometry and biology. Cambridge University Press, Cambridge.

Breed, W.G. and K.P. Aplin. 2008. The 'Uromys Group’: Papuan Old Endemics. In: (S.M. Van Dyck and R. Strahan, eds) The mammals of Australia, 3rd edition. Reed New Holland, Sydney, Australia. pp. 666.

Bryant, L.M. 2013. Cryptic diversity and evolutionary relationships among Australian closed-forest Melomys (Rodentia: Muridae) and related Australo-Papuan mosaic-tailed rats. PhD thesis, Queensland University of Technology, Brisbane, Queensland, Australia.

Bryant, L.M., S.C. Donnellan, D.A. Hurwood and S.J. Fuller. 2011. Phylogenetic relationships and divergence date estimates among Australo-Papuan mosaic-tailed rats from the Uromys division (Rodentia: Muridae). Zoologica Scripta 40: 433-447.

Claude, J. 2013. Log-Shape Ratios, Procrustes Superimposition, Elliptic Fourier Analysis: Three Worked Examples in R. Hystrix 24: 94-102.

Coates, B.J. and K.D. Bishop. 1997. A guide to the birds of Wallacea: Sulawesi, the Moluccas and Lesser Sunda Islands, Indonesia. Dove Publications, Alderley, Queensland, Australia.

Corbet, G.B. and J.E. Hill. 1992. Mammals of the Indomalayan region: a systematic review. Oxford University Press, Oxford.

DeBry, R.W. and S. Seshadri. 2001. Nuclear intron sequences for phylogenetics of closely related mammals: an example using the phylogeny of Mus. J. Mammal. 82: 280-288.

De Graciansky, P.-C., J. Hardenbol, T. Jacquin and P.R. Vail. 1998. Mesozoic and Cenozoic sequence stratigraphy of European basins. The Society of Economic Paleontologists and Mineralogists Special Publication 60.

De Jong, R. 1998. Halmahera and Seram: different histories, but similar butterfly faunas. In: (R. Hall, J.D. Holloway, eds) Biogeography and geological evolution of SE Asia. Backhuys Publishers, Leiden, Netherlands. pp. 315-325. 
Dryden, I.E. and K.V. Mardia. 1998. Statistical shape analysis. Wiley, Chichester.

Edwards, I.D., R.W. Payton, J. Proctor and S. Riswan. 1990. Altitudinal zonation of the rain forests in Manusela National Park, Seram, Maluku, Indonesia. In: (p. Baas, K. Kalkman, R. Geesink, eds.) The plant diversity of Malesia. Proceedings of the Flora Malesiana Symposium commemorating Professor Dr. C.G.G.J. van Steenis. Kluwer Academic Publishers, Leiden, Netherlands. pp. 161-175.

Esselstyn, J.A., A.S. Achmadi and K.C. Rowe. 2012. Evolutionary novelty in a rat with no molars. Biol. Lett. 8: 990-993.

Fabre, P.-H., M. Pagès, G.G. Musser, Y.S. Fitriana, J. Fjeldså, A. Jennings, K.A. Jønsson, J. Kennedy, J. Michaux, G. Semiadi, N. Supriatna and K.M. Helgen. 2013. A new genus of rodent from Wallacea (Rodentia: Muridae: Murinae: Rattini), and its implication for biogeography and Indo-Pacific Rattini systematics. Zool. J. Linnean Soc. 169: 408-447.

Flannery, T.F. 1995a. Mammals of the south-west Pacific and Moluccan Islands. Reed Books, Chatswood, New South Wales, Australia.

Flannery, T.F. 1995b. Mammals of New Guinea. Revised edition. Reed Books, Chatswood, New South Wales, Australia.

Flannery, T., P. Bellwood, P. White, A. Moore, Boeadi and G. Nitihaminoto. 1995. Fossil marsupials (Macropodidae, Peroryctidae) and other mammals of Holocene age from Halmahera, North Moluccas, Indonesia. Alcheringa 19: 17-25.

Groves, C.P. and T.F. Flannery. 1994. A revision of the genus Uromys Peters, 1867 (Muridae: Mammalia) with descriptions of two new species. Rec. Aust. Mus. 46: 145-169.

Hall, R. 1998. Biogeographic implications of the Tertiary palaeogeographic evolution of Sulawesi and Borneo. In: (R. Hall and J.D. Holloway, eds.) Biogeography and geological evolution of SE Asia. Backhuys Publishers, Leiden, The Netherlands. pp. 133-163.

Hall, R. 2002. Cenozoic geological and plate tectonic evolution of SE Asia and the SW Pacific: computer-based reconstructions, model and animations. J. Asian Earth Sci. 20: 353-434.

Hall, R. 2009. Indonesia, geology. In: (R. Gillespie and D. Clague, eds.) Encyclopedia of Islands. University of California Press, Berkeley, CA. pp. 454-460.

Hall, R. 2013. The palaeogeography of Sundaland and Wallacea since the Late Jurassic. J. Limnol. 72: 1-17.

Hall, R. and G. Nichols. 1990. Terrane amalgamation in the Philippine sea margin. Tectonophysics 181: 207-222.

Hall, R. and J.D. Holloway. 1998. SE Asian geology and biogeography: an introduction. In: (R. Hall R and J.D. Holloway, eds.) Biogeography and geological evolution of SE Asia. Backhuys Publishers, Leiden, Netherlands, 1-23.

Hall, R., M.G. Audley-Charles, F.T. Banner, S. Hidayat and S.L. Tobing. 1988. Late Palaeogene-Quaternary geology of Halmahera, Eastern Indonesia: initiation of a volcanic island arc. J. Geol. Soc. London 145: 577-590.

Haq, B.U., J. Hardenbol and P. Vail. 1987. Chronology offlfuctuating sea levels since the Triassic. Science 235: 1156-1167.

Hasagawa, H. and Syaffrudin. 1995a. Nematode fauna of the two sympatric rats Rattus rattus and $R$. exulans, in Kao District, Halmahera Island, Indonesia. J. Helminthol. Soc. Wash. 62: 27-31.

Hasagawa, H. and Syaffrudin. 1995b. Nippostrongylus marhaeniae sp. n. and other nematodes collected from Rattus cf. moro- taiensis in North Halmahera, Molucca Islands, Indonesia. J. Helminthol. Soc. Wash. 62: 111-116.

Heaney, L.R., D.S. Balete, M.L. Dolar, A.C. Alcala, A.T.L. Dans, P.C. Gonzales, N.R. Ingle, M.V. Lepiten, W.L.R. Oliver, P.S. Ong, E.A. Rickart, Jr. B.R. Tabaranza and R.C.B. Utzurrum. 1998. A synopsis of the mammalian fauna of the Philippine Islands. Fieldiana Zoology (new series) 88: 1-61.

Helgen, K.M. 2003. A review of the rodent fauna of Seram, Moluccas, with the description of a new subspecies of mosaic-tailed rat, Melomys rufescens paveli. J. Zool. (London) 261: 165-172.

Katoh, K. and H. Toh. 2010. Parallelization of the MAFFT multiple sequence alignment program. Bioinformatics 26: 1899-1900.

Kellogg, R. 1945. Two rats from Morotai Island. Proc. Biol. Soc. Wash. 58: 65-68.

Kitchener, D.J. and I. Maryanto 1993. A new species of Melomys (Rodentia, Muridae) from Kai Besar Island, Maluku Tengah, Indonesia. Rec. West. Aust. Mus. 16: 427-436.

Kitchener, D.J. and I. Maryanto. 1995. A new species of Melomys (Rodentia, Muridae) from Yamdena Island, Tanimbar group, Eastern Indonesia. Rec. West. Aust. Mus. 17: 43-50.

Kitchener, D.J. and A. Suyanto. 1996. A new species of Melomys (Rodentia, Muridae) from Riama Island, Tanimbar group, Maluku Tenggara, Indonesia. Rec. West. Aust. Mus. 18: 113-119.

Laurie, E.M.O. and J.E. Hill. 1954. List of land mammals of New Guinea, Celebes and adjacent islands 1758-1952. British Museum (Natural History), London.

Lecompte, E., K. Aplin, C. Denys, F. Catzeflis, M. Chades and P. Chevret. 2008. Phylogeny and biogeography of African Murinae based on mitochondrial and nuclear gene sequences, with a new tribal classification of the subfamily. BMC Evol. Biol. 8: 199.

Lohman, D.J., M. de Bruyn, T. Page, K. von Rintelen, R. Hall, P.K.L. Ng, H.-T. Shih, G.R. Carvalho and T. Rintelen. 2011. Biogeography of the Indo-Australian Archipelago. Annu. Rev. Ecol. Evol. Syst. 42: 205-26.

Lyons, L.A., T.F. Laughlin, N.G. Copeland, N.A. Jenkins, J.E. Womack and S.J. O'Brien. 1997. Comparative anchor tagged sequences (CATS) for integrative mapping of mammalian genomes. Nat. Genet. 15: 47-56.

Menzies, J.I. 1973. A key to rats of the genera Rattus, Melomys and Pogonomelomys of the New Guinea mainland. University of Papua New Guinea, Port Moresby.

Menzies, J.I. 1990. A systematic revision of Pogonomelomys (Rodentia: Muridae) of New Guinea. Sci. New Guinea 16: 118-137.

Menzies, J.I. 1996. A systematic revision of Melomys (Rodentia: Muridae) of New Guinea. Aust. J. Zool. 44: 367-426.

Metcalfe, I., J.M.B. Smith, M. Morwood and I. Davidson (eds). 2001. Faunal and floral migrations and evolution in SE AsiaAustralasia. Swets and Zeitlinger (AA Balkema), Leiden, The Netherlands.

Monk, K.A., Y. De Fretes and G. Reksodiharjo-Lilley (eds). 1997. The ecology of Nusa Tenggara and Malulu. The Ecology of Indonesia Series Vol. V. Periplus Editions, Hong Kong.

Musser, G.G. 1981. The giant rat of Flores and its relatives east of Borneo and Bali. Bull. Am. Mus. Nat. Hist. 169: 67-176.

Musser, G.G. 1982. Results of the Archbold Expeditions. No. 110. Crunomys and the small-bodied shrew rats native to the 
Philippine Islands and Sulawesi (Celebes). Bull. Am. Mus. Nat. Hist. 174: 1-95.

Musser, G.G. 1987. The mammals of Sulawesi. In: (T.C. Whitmore, ed.) Biogeographical evolution of the Malay Archipelago. Clarendon Press, Oxford. pp. 73-93.

Musser, G.G. 1990. Sulawesi rodents: Species traits and chromosomes of Haeromys minahassae and Echiothrix leucura (Muridae: Murinae). Am. Mus. Novit. 2989: 1-18.

Musser, G.G. 1991. Sulawesi rodents: Descriptions of new species of Bunomys and Maxomys (Muridae, Murinae). Am. Mus. Novit. 3001: 1-41.

Musser, G.G. and C. Newcomb. 1983. Malaysian murids and the Giant Rat of Sumatra. Bull. Am. Mus. Nat. Hist. 174: 327-598.

Musser, G.G. and M.E. Holden. 1991. Sulawesi rodents (Muridae, Murinae): morphological and geographical boundaries of species in the Rattus hoffmanni group and a new species from Pulau Peleng. Bull. Am. Mus. Nat. Hist. 206: 322-413.

Musser, G.G. and L.R. Heaney. 1992. Philippine rodents: definitions of Tarsomys and Limnomys plus a preliminary assessment of phylogenetic patterns among native Philippine murines (Murinae, Muridae). Bull. Am. Mus. Nat. Hist. 211: 1-138.

Musser, G.G. and L.A. Durden. 2002. Sulawesi rodents: description or a new genus and species of Murinae (Muridae, Rodentia) and its parasitic new species of sucking louse (Insecta, Anoplura). Am. Mus. Novit. 3368: 1-50.

Musser, G.G. and M.D. Carleton. 2005. Superfamily Muroidea. In: (D.E. Wilson, D.M. Reeder, eds.) Mammal species of the world: a taxonomic and geographic reference Vol. 2. Johns Hopkins University Press, 3rd edition, Baltimore, Maryland. pp. 1189-1531.

Musser, G.G. and D.P. Lunde. 2009. Systematic reviews of New Guinea Coccymys and "Melomys" albidens (Muridae, Murinae) with descriptions of new taxa. Bull. Am. Mus. Nat. Hist. 329: 5-139.

Musser, G.G., L.A. Durden, M.E. Holden and J.E. Light. 2010. Systematic review of endemic Sulawesi squirrels (Rodentia, Sciuridae), with descriptions of new species of associated sucking lice (Insecta, Anoplura), and phylogenetic and zoogeographic assessments of sciurid lice. Bull. Am. Mus. Nat. Hist., 339: 1-260.

Pagès, M., Y. Chaval, V. Herbreteau, S. Waengsothorn, J.F. Cosson, J.P. Hugot, S. Morand and J. Michaux. 2010. Revisiting the taxonomy of the Rattini tribe: a phylogeny-based delimitation of species boundaries. BMC Evol. Biol. 10: 184.

Pagès, M., E. Bazin, M. Galan, Y. Chaval, J. Claude, V. Herbreteau, J. Michaux, S. Piry, S. Morand and J.F. Cosson. 2013. Cytonuclear discordance among Southeast Asian black rats (Rattus rattus complex). Mol. Ecol. 22: 1019-1034.

Palumbi, S.R., A. Martin, S. Romano, W.O. McMillan, L. Stice and G. Grabowski. 1991. The simple fool's guide to PCR. University of Hawaii Press, Honolulu, Hawaii.

Philippe, H. 1993. MUST: a computer package of management utilities for sequences and trees. Nucleic Acids Res. 21: 5264-5272.

Posada, D. and K.A. Crandall. 1998. Modeltest: testing the model of DNA substitution. Bioinformatics 14: 817-818.

$R$ Development Core Team 2012. R: A language and environment for statistical computing. R Foundation for Statistical Computing, Vienna, Austria. Available at http://www.R-project.org.

Ramsay, E.P. 1887. Description of two new species of marsupials (Perameles and Antechinus) and of a new species of Mus (M. burtoni) from the neighbourhood of Derby, N.W.A. Proceed- ings of the Linnean Society of New South Wales (series 2) 2: 551-553.

Rohlf, F.J. 2013. tpsDIG2: Digitize landmarks and outlines from image files, scanner, or video. Available online at http://life. bio.sunysb.edu/morph/soft-dataacq.html.

Rohlf, F.J. and D.E. Slice. 1990. Extensions of the Procrustes method for the optimal superimposition of landmarks. Syst. Zool. 39: 40-59.

Ronquist, F. and J.P. Huelsenbeck. 2003. MrBayes 3: Bayesian phylogenetic inference under mixed models. Bioinformatics 19: 1572-1574.

Rowe, K.C., M.L. Reno, D.M. Richmond, R.M. Adkins and S.J. Steppan. 2008. Pliocene colonization and adaptive radiations in Australia and New Guinea (Sahul): Multilocus systematics of the old endemic rodents (Muroidea: Murinae). Mol. Phylogenet. Evol. 47: 84-101.

Rowe, K.C., K.P. Aplin, P.R. Baverstock and C. Moritz. 2011. Recent and rapid speciation with limited morphological disparity in the genus Rattus. Sys. Biol. 60: 188-203.

Rümmler, H. 1936. Die Formen der papuanischen Muridengattung Melomys. Zeitschrift für Saugetierkunde 11: 247-253.

Rümmler, H. 1938. Die Systematik und Verbreitung der Muriden Neuguineas. Mitteilungen aus dem Zoologischen Museum in Berlin 23: 1-298.

Shimodaira, H. 2002. An approximately unbiased test of phylogenetic tree selection. Sys. Biol. 51: 492-508.

Shimodaira, H. and M. Hasegawa. 2001. CONSEL: for assessing the confidence of phylogenetic tree selection. Bioinformatics 17: 1246-1247.

Sidiyasa, K. and I.G.M. Tantra. 1984. Analisis flora pohon hutan dataran rendah Wae Mual, Taman Nasional, Seram-Maluku. Bulletin Penlitian Hutan (Forest Research Bulletin) 462: 19-34.

Sikes, R.S., W.L. Gannon and Animal Care and Use Committee of the American Society of Mammalogists. 2011. Guidelines of the American Society of Mammalogists for the use of wild mammals in research. J. Mammal. 92: 235-253.

Slice, D.E. 2007. Geometric morphometrics. Annu. Rev. Anthropol. 36: 261-281.

Sody, H.J.V. 1941. On a collection of rats from the Indo-Malayan and Indo-Australian regions (with descriptions of 43 new genera, species, and subspecies). Treubia 18: 255-325.

Stattersfield, A.J., M.J. Crosby, A.J. Long and D.C. Wege. 1998. Endemic bird areas of the world: priorities for biodiversity conservation. BirdLife International, Cambridge, UK.

Swofford, D.L. 2002. PAUP*. Phylogenetic Analysis Using Parsimony (and Other Methods), 4. Sunderland, Massachusetts.

Tate, G.H.H. 1951. Results of the Archbold Expeditions. No. 65. The rodents of Australia and New Guinea. Bull. Am. Mus. Nat. Hist. 97: 183-430.

Thomas, O. 1911. New Asiatic Muridae. Ann. Mag. Nat. Hist. (series 8) 7: 205-209.

Thomas, 0.1913. Some new species of Uromys. Ann. Mag. Nat. Hist. (series 8) 12: 212-217.

Thomas, O. 1920. On mammals from Ceram. Ann. Mag. Nat. Hist. (series 9) 6: 422-431.

Thomas, 0.1921a. On a collection of rats and shrews from the Dutch East Indian Islands. Treubia 2: 109-114.

Thomas, 0.1921b. On a new genus and species of shrew, and some new Muridae from the East-Indian Archipelago. Ann. Mag. Nat. Hist. (series 9) 7: 241-250. 
Thomas, O. 1922a. A subdivision of the genus Uromys. Ann. Mag. Nat. Hist. (series 9) 9: 260-261.

Thomas, 0. 1922b. New mammals from New Guinea and neighbouring islands. Ann. Mag. Nat. Hist. (series 9) 9: 261-265.

Thomas, O. 1923. A new Uromys from the Kei Islands. Treubia 3: 422. Wallace, A.R. 1869. The Malay Archipelago: the land of the OrangUtan, and the bird of paradise. Macmillan, London.

Wallace, A.R. 1876. The geographical distribution of animals. Macmillan, London.
Watts, C.H.S. and H.J. Aslin. 1981. The rodents of Australia. Angus and Robertson, Sydney, New South Wales, Australia.

Whitmore, T.C. 1984. Tropical rain forests of the Far East. Second edition. Oxford University Press, Oxford.

Supplemental Material: The online version of this article (DOI: 10.1515/mammalia-2016-0137) offers supplementary material. 